\title{
The daily association between affect and alcohol use: A meta-analysis of individual participant data
}

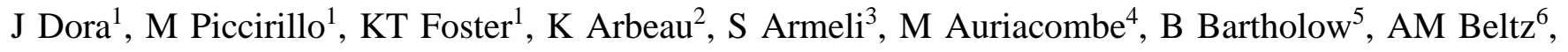
SM Blumenstock ${ }^{7}, \mathrm{~K}_{\text {Bold }}^{8}$, EE Bonar ${ }^{6}$, A Braitman ${ }^{9}$, RW Carpenter ${ }^{10}$, KG Creswell ${ }^{11}$, T De Hart ${ }^{12}$, RD Dvorak ${ }^{13}$, N Emery ${ }^{14}, \mathrm{M}_{\text {Enkema }}{ }^{1}$, CE Fairbairn ${ }^{15}$, AM Fairlie ${ }^{1}$, SG Ferguson ${ }^{16}$, T Freire ${ }^{17}$, F Goodman $^{18}$, N Gottfredson ${ }^{19}$, M Halvorson ${ }^{1}$, M Haroon $^{20}$, AL Howard ${ }^{21}$, A Hussong ${ }^{22}$, KM Jackson ${ }^{23}$, T Jenzer ${ }^{23}$, DP Kelly ${ }^{6}$, AM Kuczynski ${ }^{1}$, A Kuerbis ${ }^{24}$, CM Lee ${ }^{1}$, M Lewis ${ }^{25}$, AN Linden-Carmichael ${ }^{26}$, A Littlefield ${ }^{27}$, DM Lydon-Staley ${ }^{28}$, JE Merrill ${ }^{23}, \mathrm{R}$ Miranda Jr. ${ }^{23}, \mathrm{C}$ Mohr $^{29}, \mathrm{JP}_{\text {Read }}{ }^{30}, \mathrm{C}_{\text {Richardson }}{ }^{31}$, R O’Connor ${ }^{32}$, SS O’Malley ${ }^{8}$, L Papp $^{33}$, TM Piasecki ${ }^{33}, \mathrm{P} \mathrm{Sacco}^{34}$, N Scaglione ${ }^{35}$, F Serre ${ }^{4}$, J Shadur ${ }^{36}$, KJ Sher ${ }^{5}$, Y Shoda ${ }^{1}$, TL Simpson ${ }^{1,37}$, MR Smith ${ }^{1}$, A Stevens ${ }^{23}$, B Stevenson ${ }^{38}$, H Tennen ${ }^{39}$, M Todd ${ }^{40}$, H Treloar Padovano ${ }^{23}$, T Trull ${ }^{5}$, J Waddell ${ }^{40}$, K Walukevich-Dienst ${ }^{1}$, K Witkiewitz ${ }^{41}$, $\mathrm{T}$ Wray $^{23}$, AGC Wright $^{42}$, AM Wycoff ${ }^{5}, \mathrm{KM} \mathrm{King}^{1}$

\author{
${ }^{1}$ University of Washington \\ ${ }^{2}$ Trinity Western University \\ ${ }^{3}$ Fairleigh Dickinson University \\ ${ }^{4}$ Université de Bordeaux \\ ${ }^{5}$ University of Missouri-Columbia \\ ${ }^{6}$ University of Michigan \\ ${ }^{7}$ Indiana University \\ ${ }^{8}$ Yale University \\ ${ }^{9}$ Old Dominion University \\ ${ }^{10}$ University of Missouri-St. Louis \\ ${ }^{11}$ Carnegie Mellon University \\ ${ }^{12}$ Loyola University Chicago \\ ${ }^{13}$ University of Central Florida \\ ${ }^{14}$ Colorado State University
}

\author{
${ }^{15}$ University of Illinois at Urbana- \\ Champaign \\ ${ }^{16}$ University of Tasmania \\ ${ }^{17}$ University of Minho \\ ${ }^{18}$ University of South Florida \\ ${ }^{19}$ Research Triangle Institute \\ ${ }^{20} \mathrm{New}$ York University \\ ${ }^{21}$ Carleton University \\ ${ }^{22}$ University of North Carolina \\ ${ }^{23}$ Brown University \\ ${ }^{24}$ Hunter College of the City Univer- \\ sity of New York \\ ${ }^{25}$ University of North Texas \\ ${ }^{26}$ Pennsylvania State University \\ ${ }^{27}$ Texas Tech University
}

\author{
${ }^{28}$ University of Pennsylvania \\ ${ }^{29}$ Portland State University \\ ${ }^{30}$ University of Buffalo \\ ${ }^{31}$ Illinois College \\ ${ }^{32}$ Concordia University \\ ${ }^{33}$ University of Wisconsin \\ ${ }^{34}$ University of Maryland \\ ${ }^{35}$ University of Florida \\ ${ }^{36}$ George Mason University \\ ${ }^{37}$ VA Puget Sound Healthcare System \\ ${ }^{38}$ University of Minnesota \\ ${ }^{39}$ University of Connecticut \\ ${ }^{40}$ Arizona State University \\ ${ }^{41}$ University of New Mexico \\ ${ }^{42}$ University of Pittsburgh
}

Note: This paper has been accepted for publication at Psychological Bulletin.

Correspondence concerning this article should be addressed to Jonas Dora, Department of Psychology, University of Washington, Seattle. E-mail: jonas.dora.psych@gmail.com 


\begin{abstract}
Influential psychological theories hypothesize that people consume alcohol in response to the experience of both negative and positive emotions. Despite two decades of daily diary and ecological momentary assessment research, it remains unclear whether people consume more alcohol on days they experience higher negative and positive affect in everyday life. In this preregistered meta-analysis, we synthesized the evidence for these daily associations between affect and alcohol use. We included individual participant data from 69 studies $(N=12,394)$, which used daily and momentary surveys to assess affect and the number of alcoholic drinks consumed. Results indicate that people are not more likely to drink on days they experience high negative affect, but are more likely to drink and drink heavily on days high in positive affect. People self-reporting a motivational tendency to drink-to-cope and drink-to-enhance consumed more alcohol, but not on days they experienced higher negative and positive affect. Results were robust across different operationalizations of affect, study designs, study populations, and individual characteristics. These findings challenge the long-held belief that people drink more alcohol following increases in negative affect. Integrating these findings under different theoretical models and limitations of this field of research, we collectively propose an agenda for future research to explore open questions surrounding affect and alcohol use.
\end{abstract}

Analysis code, supplementary material: https://osf.io/jcr2q/

Keywords: affect, alcohol use, drinking motives, emotion, meta-analysis

The associations between emotions and behavior are of core interest across various disciplines of psychology. One of the most theorized and studied associations is the link between emotions and substance use. The vast majority of research on this association has focused specifically on alcohol use. Harmful alcohol use represents one of the top four contributors to noncommunicable diseases globally (along with tobacco use, physical inactivity, and unhealthy diets), and the World Health Organization estimates that alcohol use is the cause of roughly five percent $(\sim 3,000,000)$ of all deaths worldwide annually (World Health Organization, 2018). The health-related and economic costs of alcohol use alone are estimated to exceed one percent of the gross national product of high- and middle-income countries (Rehm et al., 2009). In the United States, roughly 15 million adults meet criteria for alcohol use disorder (AUD; SAMHSA, 2021), which is characterized by a pattern of alcohol use that persists despite experiencing negative biological, behavioral, cognitive, and social consequences (American Psychiatric Association, 2013). Thus, understanding the robustness of the association between emotions and alcohol use in people's daily lives has broad appeal for improving psychological theory regarding mental and behavioral health, as well as the practice of using psychological science to enhance health, lengthen life, and reduce illness and disability.

Multiple theoretical accounts proposed hypothesize that alcohol use is, at least partially, motivated by the desire to regulate one's affective state (e.g., Baker et al., 2004; Cloninger, 1987; Conger, 1956; Cooper et al., 1995; Cox \& Klinger, 1988; Koob \& Le Moal, 2008). Although each model proposes distinct aspects of how these affect-alcohol associations develop (e.g., allostatic load, social learning, operant conditioning), there is a general proposition that people often drink to relieve their negative emotions or to enhance positive emotions. Furthermore, affect-driven negative and positive reinforcement processes may lead to escalations in alcohol use and AUD for some individuals. Accordingly, the societal costs of problematic alcohol use could be lessened by targeting the affect-alcohol association.

\section{Theories of affect relating to alcohol use}

Many theoretical models predict that people's emotional experiences are related to their alcohol use (e.g., Baker et al., 2004; Conger, 1956; Cooper et al., 1995; Cox \& Klinger, 1988; Koob \& Le Moal, 2008; Wills \& Filer, 1996). Inspired by early work on reinforcement learning in animals (Conger, 1956) and humans (Sutton $\&$ Barto, 2018), these models share the core assumption that alcohol use is reinforcing through its mood-altering effects. That is, theories generally state that people's mood should improve following the use of alcohol, and that in turn negative emotional experiences should motivate people to drink. Although mood improvement could result from negative affect decreasing or positive 
affect increasing, theories do not explicitly state whether high positive affect should precede alcohol use. Furthermore, there is a lack of specificity regarding the population that is most likely to demonstrate an association between negative affect and subsequent alcohol use. The motivational models of Cox and Klinger (1988) and Cooper and colleagues (1995) state that people in general are motivated to drink alcohol to cope with negative affect and to drink to enhance positive affect as they learn this association through repeated pairing of alcohol relieving negative affect or improving positive affect (Skinner, 1969). Although they describe how this pathway can lead to AUD for some, they also suggest that alcohol use regulates affect also in those without the disorder. Later models by Baker and colleagues (2004) and Koob and Le Moal (2008) specifically state that negative affect should motivate alcohol use in people with a history of severe AUD. However, Koob and Le Moal (2008) also argue that in the early stages of the progression to AUD, people use alcohol because of its positively reinforcing properties, but in later stages of the disorder alcohol use is negatively reinforcing in that it relieves symptoms of alcohol withdrawal. Finally, the models by Wills and Filer (1996) and Kaplan (1984) describe the development of stress-motivated substance use in adolescents, in which deviant behaviors (including alcohol use) are a coping strategy that alleviates self-derogation in teens. In summary, models of affect and alcohol use imply similar hypotheses about the negative affect - alcohol use association. Importantly, the models do not clearly specify the time scale at which these associations should be observed, whether all negative emotions should motivate alcohol use equally, or whether negative affect should influence the frequency or quantity of alcohol use.

The earliest affect-regulation models were specific to alcohol use (Conger, 1956). However, similar motivational processes have been theorized to drive problematic or heavy engagement in other behaviors that can become addictive or dysregulating over time. For example, a comparable affect-regulation model has been proposed to explain binge eating (Hawkins \& Clement, 1984), and a meta-analysis of ecological momentary assessment (EMA) studies found evidence that negative affect precedes binge eating episodes (HaedtMatt \& Keel, 2011). Similarly, recent meta-analyses found negative affect to predict smoking in longitudinal studies of both light and heavy smokers (Akbari et al., 2020) and to predict suicidal injury, thoughts, and behaviors in EMA studies (Kuehn et al., 2022). In short, there is relatively consistent evidence that affect, particularly negative affect, plays a role in the development and maintenance of behaviors with addictive or dysregulating potential.

\section{Empirical tests of affect relating to alcohol use}

There is robust evidence that people consume more alcohol following experimental manipulations of affect (Bresin, Mekawi, \& Verona, 2018) and experience changes in affect while drinking in lab settings (Sayette, 2017; Smith, 2013; Wilkie \& Stewart, 2005). Experimental studies have the advantage of demonstrating causal effects but by nature of their design can only demonstrate that affect causes alcohol use when affect immediately precedes a drinking opportunity, when alcohol is freely and immediately available, is unlikely to interfere with actively coping with the stressor, and when drinking would have no impact on later responsibilities (participants are usually not allowed to leave the laboratory before their BAC has fallen below .04 dl/L; Bacon et al., 2015; de Wit et al., 2003). Consequently, experiments are limited in their ability to explain how affect regulation might influence drinking in people's natural contexts.

Evidence from global self-report data indicates that many people believe that drinking either relieves their negative affect or enhances their positive affect (Leigh, 1989), and that people consistently report emotion regulation as a major motivator for their alcohol use (Cooper, 1994). A recent meta-analysis of mostly cross-sectional studies revealed that people endorsing higher coping (with negative affect) and enhancement (of positive affect) motives tend to report higher drinking frequency and quantity (Bresin \& Mekawi, 2021). The same meta-analysis found in longitudinal studies that enhancement (but not coping) motives were associated with later alcohol use (both were associated with later alcohol-related problems). Thus, if affect regulation does influence alcohol use, it does so at longer time scales (such as months or years) than at the daily or weekly level. sRetrospective global self-report information is limited because people often have poor insight into the causes of their behavior (Mazar \& Wood, 2022; Nisbett \& Wilson, 1977). For example, recent research has shown that people who report that they tend to act on impulse when they are upset do not exhibit stronger associations between affect and impulsivity in daily life (Feil et al., 2020; Sharpe et al., 2020). Studies in people's natural environments using daily diary and EMA methods are necessary to establish the plausibility of affect regulation hypotheses and to test within- 
person processes in everyday life. Support for the core prediction of motivational models of alcohol use that in naturalistic environments people drink following experiences of negative affect, remains elusive.

Dozens of daily diary and EMA studies have assessed participants' self-reported mood once to several times per day, and reported number of alcoholic drinks they have consumed each day or evening. This repeated sampling of participants' momentary subjective experiences and behavior attempts to minimize recall error/bias and maximize ecological validity (Shiffman, 2009). Most diary and EMA studies of affect regulation have been predominantly conducted with college student (e.g., Arbeau et al., 2011; Hussong et al., 2005; O'Hara et al., 2014; Stevens et al., 2020) and community samples (e.g., Armeli et al., 2000; Collins et al., 1998; Duif et al., 2020; O’Donnell et al., 2019). Most of these studies sampled people who drink regularly, with some studies oversampling heavy drinkers (e.g., Emery \& Simons, 2020). Relatively few of them (e.g., Jahng et al., 2011; Wycoff et al., 2020) have been conducted in clinical samples of any kind, and even fewer have been conducted with clinical samples of people with AUDs or who are seeking or in treatment (e.g., Bold et al., 2017). Given that some affect regulation theories predict negative affect to motivate alcohol use in all of these populations (Cooper et al., 1995; Cox \& Klinger, 1988), whereas other models (Baker et al., 2004; Koob \& Le Moal, 2008) posit that negative affect should motivate alcohol use specifically in people with AUD, this literature has provided more tests of the former compared to the latter.

Most studies predicted drinking from both general negative and positive affect scores (e.g., Emery \& Simons, 2020; Howard et al., 2015; Wycoff et al., 2020), which are calculated by taking the average across reports of multiple discrete emotions (such as anxious, irritable, and angry). This is in line with seminal work indicating that these are the two dominant and independent dimensions of self-reported affect that differ only in valence and are high in arousal (negative \& positive; Watson et al., 1988; Zevon \& Tellegen, 1982), and it assumes that discrete emotions of similar valence relate to alcohol use in a similar way. In contrast, a popular alternative model of the structure of affect assumes that emotions differ along valence and arousal (Russell, 1980). However, exactly which emotions are included in these affect indices has varied across studies. Reviewing the literature, we found that studies usually assessed negative and positive affect with three to ten items each from a pool of roughly 100 emotion words. While these items often differ in valence and arousal, they are usually combined and described as reflecting the dimensions of negative and positive affect proposed by Watson and colleagues (1988). In other words, although the dominant theoretical conceptualization of negative and positive affect in this literature is around high arousal positive and negative affect, the actual measurement of affect has frequently incorporated low arousal items (such as sad or calm) into the averaged measures of negative and positive affect. This jingle fallacy (where different measures have similar labels) may obscure the true effect of affective states if there are key differences between high and low arousal states. Some studies also have attempted to predict drinking from discrete emotions (e.g., Dvorak \& Simons, 2014; Swendsen et al., 2000) or the variability in affect prior to a drinking event (e.g., Gottfredson \& Hussong, 2013; Mohr et al., 2013). In summary, studies differ considerably in how they operationalized affect, and one important sensitivity analysis of the present study was to test the degree to which the operationalization of affect influenced the findings. Whether some emotional states motivate alcohol use more than others is an open question.

How alcohol use is operationalized has also varied widely across studies. Many studies predicted a variety of outcomes such as the likelihood of drinking and drinking quantity (e.g., Dora et al., 2022; Dvorak \& Simons, 2014; O'Donnell et al., 2019), the likelihood of heavy drinking (e.g., Bold et al., 2017; Collins et al., 1998; Howard et al., 2015), time-to-drink (e.g., Armeli et al., 2008; Hussong, 2007; Littlefield et al., 2012; Todd et al., 2009), or changes in affect leading up to a drinking episode (Courtney \& Russell, 2021; Russell et al., 2020; Treloar et al., 2015). Although all of these outcomes reflect alcohol use, they do not necessarily provide a test of the same hypothesis. For example, given the verbal formulation of motivational models of alcohol (Cooper et al., 1995; Cox \& Klinger, 1988), it is unclear how to reconcile a finding that negative affect increases prior to a drinking event in one sample (e.g., Treloar et al., 2015) but does not predict the likelihood to drink in another sample (e.g., O'Donnell et al., 2019).

A variety of moderators and mediators have been proposed and tested in previous studies, such as drinking motives (e.g., Ehrenberg et al., 2016; Gautreau et al., 2015; Grant et al., 2009; Hussong et al., 2005; Stevenson et al., 2019; Wycoff et al., 2020), urgency (e.g., Bold et al., 2017; Dora et al., 2022; Simons et al., 2010), and craving (Waddell et al., 2021). The most commonly examined moderators of the affect-alcohol 
use association in everyday life are the drinking motives people report. Rooted in Gray's inhibition and activation model (Gray, 1982), motivational models of alcohol use assume (i) that people hold explicit motives to cope with negative affect and enhance positive affect, (ii) that people can consciously report on these motives, and (iii) that these motives underlie their drinking behavior. Drinking motives are thought to develop as a function of drinking experience and social learning (Cox \& Klinger, 1988; McClelland et al., 1989). Following this reasoning, studies have tested whether the link between negative/positive affect and alcohol use in everyday life is stronger for people who report stronger coping/enhancement motives.

Differences in study approaches can be traced back to the relative non-specificity inherent to theoretical models of affect regulation (van Rooij \& Baggio, 2021), which complicate a narrative synthesis of the existing literature. Although the theoretical predictions of affect regulation models have been refined over time (Hussong, Jones, Stein, Baucom, \& Boeding, 2011; Koob \& Le Moal, 2008), most empirical research has failed to take advantage of these advances. The most common test in the literature asks whether affect reported during the day is associated with alcohol use that same day or evening. Looking at the literature as a whole, some data suggest that people are more likely to drink and consume more alcohol on days characterized by increased experiences of increased negative (e.g., Armeli et al., 2000; Park et al., 2004; Simons et al., 2005) or positive (e.g., Dora et al., 2022; Emery \& Simons, 2020; Howard et al., 2015) affect, while other studies presented null findings for negative (e.g., Courtney \& Russell, 2021; Dora et al., 2022; Duif et al., 2020; Ehrenberg et al., 2016; Littlefield et al., 2012) and positive affect (e.g., Dvorak et al., 2014; O’Donnell et al., 2019; Sacco et al., 2015). Infrequently, negative affect was estimated to lead to a reduction in subsequent alcohol use (Aldridge-Gerry et al., 2011; Bresin \& Fairbairn, 2019; Russell et al., 2020). At the same time, studies that do report significant findings often do so in the context of moderators that condition the affect-alcohol association (e.g., Dvorak \& Simons, 2014; Simons, Dvorak, Batien, \& Wray, 2010). A recent systematic review concluded that evidence for the hypothesized interactions between affect and drinking motives is equivocal (Votaw \& Witkiewitz, 2021).

\footnotetext{
${ }^{1}$ The focus was placed on these two models over related models of affect and alcohol use as most studies in this field have been conducted in non-clinical samples.
}

Thus, the primary goal of this study was to synthesize the evidence for the two main propositions of motivational models of alcohol use ${ }^{1}$ (Cooper et al., 1995; Cox \& Klinger, 1988):

Proposition 1: Affect motivates alcohol use in everyday life.

Proposition 2: This effect is stronger in people with explicit drinking motives related to affect regulation.

\section{Hypotheses}

We preregistered two hypotheses derived from the propositions of motivational models of alcohol use. We hypothesized that negative and positive affect should both be associated with alcohol use on a daily level, such that people are more likely to drink and to consume more drinks on days they report negative or positive affect that is higher than usual (Hypotheses 1a + b). We also hypothesized that these associations should be stronger for people who self-report a disposition to drink-to-cope with negative emotions (coping motives) and drink-to-enhance positive emotions (enhancement motives), respectively (Hypotheses $2 a+b$ ).

\section{Our methodological approach}

Much of the research reviewed above was conducted prior to Open Science initiatives towards replicability (Open Science Collaboration, 2015), which remains relatively underappreciated in clinical science (Tackett et al., 2019). Many studies employed rather small samples ( $<100$ participants), none are direct replications of prior studies, and almost no analyses were preregistered (for an exception, see Dora et al., 2022). A standard meta-analytic approach using aggregated study data would not be able to accurately synthesize this literature for several reasons. The most common outcome variable in this literature is the number of alcoholic drinks consumed each day or evening, which is a zero-inflated count variable. Given the different dataanalytic approaches researchers have used (e.g., [generalized] linear mixed-effects modeling using linear, binomial, [zero-inflated \& hurdle] Poisson and negative binomial outcome distributions with varying random effects structures), it is not possible to extract and meaningfully compare effect sizes from the published literature. Meta-analyzing such datasets can be 
achieved using individual participant data meta-analysis, in which the raw data from each study is used to build a large model that accounts for variation between participants and datasets. Such an individual participant data meta-analysis is superior for several additional reasons (Cooper \& Patall, 2009). For example, it allowed us to analyze the data using unified operationalizations of affect and alcohol use (including data from unpublished studies) and using a unified data-analytic protocol.

Even equipped with the raw data from many studies, we had to make many analytic decisions along the way. Which data do we include in our analyses? How do we operationalize "affect" and "alcohol use"? At what time scale do we test this association? What is our smallest effect size of interest? We used three principles to guide these decisions. First, we looked for agreement in published work, as we are of the opinion that a meta-analysis should reflect the literature it synthesizes. For example, in our main analyses we predicted drinking frequency and quantity from general negative and positive affect, since these are the tests most commonly reported in the literature. Second, for our main analyses we gave preference to decisions that would allow us to include the most data. For example, in our main analyses we predicted alcohol use from daily affect, since many studies were designed with this test in mind. Third, we collectively made decisions involving the entire co-author team, which was comprised of experts on affect, alcohol use, and EMA research (some are experts on all three). We held individual Zoom and telephone meetings with the majority of co-authors, exchanged thousands of emails throughout the project, and conducted online polls to gather feedback at every stage of the project. For example, co-authors completed a poll to give qualitative and quantitative feedback on the pre-registration, such as voting on the interpretation of different effect sizes. Co-authors were also given ample opportunity to share their interpretations of the results and shape revisions on this manuscript.

A further complication is variation across studies on measurement, study population, study designs, and data-analytic decisions. It is unclear whether the hypothesized associations exist in the broader population, whether they only exist in specific sub-populations or drinking situations, whether they might only be found when choosing certain study designs or making some data-analytic decisions (versus others), or whether associations between affect and alcohol use should be expected to be entirely absent. Clarifying these open questions is of critical importance as they have broad implications for our scientific understanding of the development, prevention, and treatment of problematic alcohol use. For that reason, the secondary goal of this study was to explore extent to which the effects were robust in sensitivity analyses and potentially differ along individual- and study-level moderators.

\section{Sensitivity and moderator analyses}

As truly confirmatory tests require researchers to choose one path through the 'garden of forking dataanalytic decisions' (Gelman \& Loken, 2013; Wagenmakers et al., 2012) and analyzing EMA data requires them to make many such decisions, we preregistered several sensitivity analyses to test whether our results were contingent on any such choices. First, researchers in this literature assess many different combinations of emotions, but we had to decide on one $o p$ erationalization of affect. Thus, we derived a total of three alternative operationalizations of negative and positive affect from the literature to test whether specific sets of emotion items influence any potential association between affect and alcohol use. Second, in addition to our main analyses of EMA and daily diary data, we attempted to establish a temporal association by analyzing a subset of the data in which we were able to ensure that any report of affect preceded the onset of alcohol use on that day. Third, we tested whether the timing of emotion reports (morning vs afternoon) influences any potential association between affect and alcohol use. Collectively, these sensitivity analyses were meant to test the robustness of the affect-alcohol use association in light of different valid analytic decisions.

We preregistered several moderator analyses to explore the extent to which any potential affect-alcohol use association may only be observed in certain study designs or subpopulations. For example, we explored whether the finer granularity of multiple daily surveys might be necessary to observe an association by testing whether effects differ between daily diary and EMA studies. We also explored whether negative affect is a stronger predictor in clinical populations (e.g., Baker et al., 2004) by testing the moderating effect of study population (college vs community vs clinical). Unfortunately, we did not have a measure of AUD symptoms on the participant level in most datasets. As an imperfect proxy, we explored whether the associations might be stronger for heavy compared to light drinkers (based on both self-reports of alcohol use and study inclusion criteria at the sample- and participant-level). We also explored age as a moderator, as some theoretical mod- 
els posit differences in the affect-alcohol use association between adolescents and young adults (Hussong et al., 2011; Wills \& Filer, 1996). We tested gender as a moderator, as there are historical differences in the rates of alcohol use and the experience of emotions across males and females (Harder et al., 2014). Finally, we tested time of the week (e.g. weekend vs. weekday), as there is a strong temporality to alcohol use (Room et al., 2012). Collectively, these moderator analyses were meant to illuminate the extent to which associations between affect and alcohol use are contingent on the study design and might differ between study populations or participants.

\section{Method}

\section{Transparency and openness}

This research was approved by the local Institutional Review Board. We preregistered our hypotheses and statistical analyses after obtaining all the data included in our analyses but before we processed and analyzed the data. All decisions described hereafter were preregistered unless otherwise noted. The authorship team provided input on the preregistration and analytic decisions; thus, analytic decisions generally reflect the consensus of the author team, and we used sensitivity analyses to test questions where there was more disagreement about specific analytic decisions. Although we do not have permission to share our data publicly, our preregistration, analysis script, and $\mathrm{R}$ output are available on the Open Science Framework project of this article (https://osf.io/jcr2q/).

\section{Inclusion Criteria}

We included studies that met the following criteria:

1. The study collected data from human participants of any age, study population, or drinking behavior.

2. The study employed a diary (surveyed once daily) or ecological momentary assessment (surveyed multiple times daily) design.

3. The study assessed the total number of alcoholic drinks consumed each day or evening.

4. The study assessed negative affect or positive affect with at least two items.

\section{Systematic search strategy}

We searched for raw data that fit our inclusion criteria in three ways (see Figure 1). First, we searched for articles published between Jan 1, 2000 and Jan 1, 2021 via Web of Science ${ }^{2}$ using the following search terms: Topic $=(($ Negative emotion OR Negative affect OR Positive emotion OR Positive affect) AND (Alcohol use OR Alcohol intoxication OR Alcohol drink*) AND (Ecological momentary assessment OR Ambulatory assessment OR Experience sampling OR Diary)). This search resulted in 214 hits. We screened all studies by reading the abstract and method section to assess whether the study might fit our inclusion criteria, retaining studies that satisfied inclusion criteria 1,2 , and either 3 or 4 (since studies assessing affect might have assessed alcohol use as well without publishing it and vice versa). Second, after removing 127 studies that did not fit our inclusion criteria, we consulted the reference sections of the 87 studies that met the inclusion criteria, which yielded 27 additional articles, for a total of 114 studies that fit the inclusion criteria. We contacted the 62 corresponding authors of the 114 potentially eligible studies, asking them to contribute any raw published and/or unpublished data that fit our inclusion criteria. Third, we asked researchers who agreed to share data with us whether they were aware of additional researchers who we might contact for data, resulting in the contact of 27 additional researchers. We followed up with all researchers at least twice to include as many datasets in the meta-analysis as possible. In the end, we received 69 eligible raw datasets from 49 researchers, which we then combined for our meta-analytic analyses. All studies measured affect and alcohol use daily for multiple days per participant. Additionally, 48 datasets contained a measure of drinking motives.

\section{Studies and participants}

We used individual participant data from 69 studies comprising data collected in Australia, Canada, France, and the United States (see https://osf.io/jcr2q/ for an overview of studies included in this meta-analysis). Twenty-six studies surveyed participants once daily, and 43 studies surveyed participants multiple times daily. Studies sampled college students $(k=28)$, from the community $(k=31)$, and from clinical populations

\footnotetext{
${ }^{2}$ We also searched APA PsycInfo and Google Scholar but did not find any additional articles using the same search terms.
} 


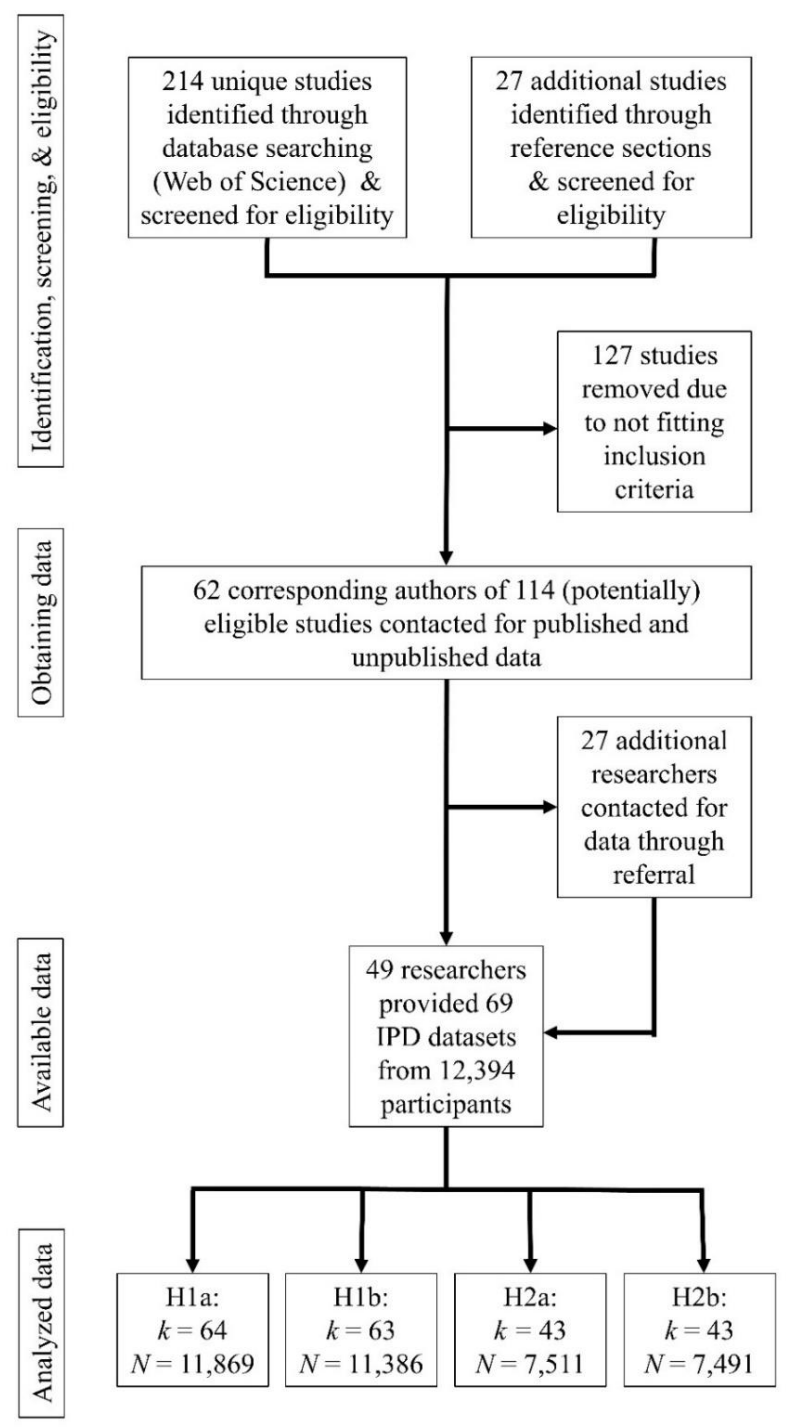

Figure 1. Selection procedure of included studies. $k=$ number of datasets; $N$ = number of participants; H1a: Daily association between negative affect and alcohol use. H1b: Daily association between positive affect and alcohol use. H2a: Cross-level interaction between negative affect and coping motives on alcohol use. H2b: Cross-level interaction between positive affect and enhancement motives on alcohol use.

$(k=10)$. Participants in clinical samples were in treatment for alcohol and substance use $(k=7)^{3}$, borderline personality disorder $(k=1)$, chronic pain $(k=1)$, and diagnosed with social anxiety $(k=1)$. The sample sizes

\footnotetext{
${ }^{3}$ Two studies included a treatment group that was administered naltrexone. Naltrexone changes the reinforcing properties of alcohol, which might support an argument to exclude these data. Based on the recommendation of the authors of those studies, and because of the relatively low number of treatment studies in general, we opted to preregister that we would include these studies in the results
}

in the included datasets ranged from $N=34-1,421$ participants, resulting in a combined dataset of 12,394 participants (55.4\% female; $74.6 \%$ White Age: $M=23.53$, $S D=10.03 ; \min =13 ; \max =92 ;)$. Studies gathered daily data for a minimum of seven and a maximum of 120 days $(M=24.23, S D=19.94)$, resulting in a combined 353,762 possible daily observations. Alcohol use data were available on $73.4 \%$ of study days across all studies $\left(S D_{\text {study }}=18.3 \% ; \min _{\text {Study }}=37.9 \% ;\right.$ max $_{\text {Study }}=$ $100 \%$ ) resulting in 259,700 daily observations and 82,266 reported drinking days.

\section{Measures}

Alcohol use. In all studies, participants reported how many alcoholic drinks they had consumed; this was either logged during the drinking event, assessed in the evening of the same day, or assessed the next day. Next-day reports reflect either drinking over the previous day or the previous evening. Response options for this item varied between studies (i.e., the end-point of the scale ranged from ' 5 drinks or more' to an openended report of drinks).

In cases where the response options were smaller or larger than one unit, we recoded the number of drinks to the lower unit value (e.g., 1.5 drinks $=1 ; 1-2$ drinks $=1 ; 3-4$ drinks $=3$ ), because choosing the mid-point of the bin is likely to over-estimate the true value (McGinley \& Curran, 2014). In cases where alcohol use was reported since the last assessment, we reverse-lagged morning reports because drinks reported in the morning most likely were consumed the night before and thus count towards the previous day's drinking-event. We winsorized alcohol reports of more than 20 drinks, recoding any entry of more than 20 drinks to 20 drinks, to limit the tail of the count distribution. This resulted in $0.02 \%$ of cases being winsorized, which ultimately had no influence on the results.

Negative affect and positive affect. The included datasets contain a total of 64 different negative affect items (e.g., anxious, disappointed, frustrated, guilty, irritable) and 36 different positive affect items (e.g., cheerful, determined, enthusiastic, happy, proud; see

to maximally represent clinical data. Sensitivity analyses suggested that there were no differences between treatment and non-treatment seeking samples, suggesting that the inclusion of treatment samples who were administered naltrexone would not change the conclusions in the current study. 
https://osf.io/jer2q/ for an overview of all included affect items). The items were answered on a range of different scales (4-point, 5-point, 6-point, 7-point, 8-point, 10-point, 11-point, 12-point, $0-100$ scale) and refer to a range of different time frames (right now, since last assessment, past 5 minutes, past 15 minutes, past 30 minutes, past 1 hour, past 2 hours, past 24 hours, today, yesterday). In the included EMA studies, participants reported their momentary affect throughout the day. In the included diary studies, participants mostly reported that day's affect together with the previous day's alcohol use.

For our main analyses, we used the negative and positive mood items that were part of the 33 negative affect and 24 positive affect items derived in earlier factor-analytic research (Zevon \& Tellegen, 1982) to harmonize the variable across studies. We included data from studies provided the study collected at least two negative and/or positive affect items, respectively, from that inventory (this resulted in the exclusion of six and seven datasets for the negative and positive affect analyses respectively, which did not assess at least two of these items). First, we converted all items to the same scale using the percent of maximum possible score $(\mathrm{POMP})$ procedure (Cohen et al., 1999): $\mathrm{POMP}=[(\mathrm{ob}-$ served - scale minimum)/(scale maximum - scale minimum) $] \times 100$. Then, we averaged all assessed negative and positive mood items respectively for each daily assessment. For diary studies, this was the daily negative and positive affect scores. For EMA studies, we averaged the negative and positive mood scores for each assessment into a daily negative and a daily positive affect score. Our negative and positive affect variables showed high internal reliability across items $\left(\mathrm{R}_{\mathrm{kRn}}{ }_{\mathrm{NA}}=\right.$ $.99, \mathrm{R}_{\mathrm{kRn}}{ }_{\mathrm{PA}}=.99$ ) and time (Revelle, 2016; Shrout \& Lane, 2012).

Coping and enhancement motives. Forty-four studies $(63.8 \%$ of total) measured dispositional coping (e.g., "I drink to forget my worries.") and enhancement motives (e.g., "I drink because it is fun.") at baseline via the respective coping and enhancement subscales of the Drinking Motives Questionnaire (DMQ; Cooper, 1994). One study (1.5\% of total) measured coping and enhancement motives daily via the respective coping and enhancement subscales of the DMQ. Two studies (3\% of total) measured coping motives at baseline via the alcohol and drug use subscale of the COPE inventory (Carver et al., 1989). One study (1.5\% of total) measured coping and enhancement motives via a list of items which mirror a subset of the DMQ items (e.g., "Unpleasant emotions [angry, frustrated, sad, anxious] trigger my drinking."; "Pleasant emotions [when enjoying yourself or feeling happy] trigger my drinking").

We converted all motives items onto the same scale using the POMP procedure. For studies measuring motives at baseline, we averaged all available items of the respective scale. For the study measuring motives daily, we averaged all available items measured across all days of assessment. We did not assess the internal reliability of our motives measure as in multiple cases we received scale scores rather than scores per individual item. Both coping and enhancement motives have exhibited high internal consistency in previous research (Dvorak et al., 2014; Littlefield et al., 2012; Waddell et al., 2021).

\section{Meta-analytic moderators}

Decisions concerning whether a dataset was included in the meta-analysis were based on the inclusion criteria above. Once co-authors agreed to contribute the relevant variables, we asked them if they had additional variables that we could examine as meta-analytic moderators. A few variables we were interested in were only accessible in a small number of datasets $(k<5)$, and hence were removed from further consideration (daily drinking motives, alcohol expectancies, AUD symptoms). Labeling of moderators was based on information provided by the contributing co-authors. Whenever these were not straightforward, the first author contacted the contributing co-author, and the labeling was determined together. We collected the following variables for the majority of datasets to test for their influence on our meta-analytic conclusions:

Study design. We coded studies as employing either a diary or EMA design. Studies were coded as diary design if they collected data from participants once per day and were coded as EMA design if they collected data from participants more than once per day.

Study population. We coded studies as sampling from a college, community, or clinical population. Studies were coded as sampling from a college population if they only included university students. They were coded as sampling from a clinical population if one of the inclusion criteria was a medical or psychological diagnosis of any kind. Otherwise, the study was coded as a community sample.

Study treatment. We coded whether a study involved any cognitive, behavioral, medical, pharmacological, or campaign treatment or intervention (or a combination of these). Included treatment studies primarily targeted substance use disorders (e.g., motiva- 
tional interviewing, cognitive behavioral therapy, naltrexone administration) with one study including participants in treatment for lower back pain and one study including participants in treatment for borderline personality disorder (two groups at risk for developing substance use disorders).

Study inclusion criterion (heavy/light alcohol drinkers). We coded whether a study included only participants who were moderate or heavy drinkers (vs including infrequent or light drinkers) according to CDC guidelines (Centers for Disease Control and Prevention, 2018). The CDC defines a moderate drinker as someone who consumes more than 3 drinks per week but no more than 7 drinks per week for women and no more than 14 drinks per week for men. Heavy drinkers are defined as those consuming more than 7 drinks per week for women and 14 drinks per week for men.

Study length. We coded the number of days participants received daily diary/EMA surveys.

Participant self-reported alcohol use at baseline. For studies that assessed self-reported alcohol use at baseline (e.g., via the Daily Drinking Questionnaire or a 7-day Timeline Follow-Back; Collins et al., 1985; Hoeppner et al., 2010), we calculated the average number of alcoholic drinks a participant reported to consume per week.

Participant age and sex. Collaborators shared with us participants' age in years as well as their biological sex (gender, in studies that did not assess sex).

Time of week. From survey completion dates, we coded whether or not observations were completed during the social weekend (Thursday, Friday, Saturday vs remaining weekdays), as people drink alcohol most often on these three days (Dora, Schultz, Shoda, et al., 2022; Finlay et al., 2012).

\section{Data analysis}

We conducted all of our analyses in R ( $\mathrm{R}$ Core Team, 2021). To calculate the meta-analytic effect sizes relating to our hypotheses, we used a mixed-effects modeling approach to account for nesting of observations within persons and of persons within studies. We fitted these models under a Bayesian framework to be able to quantify the plausibility of a range of effect sizes of interest, consistent with our pre-registered focus on effect size estimation. This is particularly helpful with such a large sample size, as many trivial effects might have been statistically significant. Because alcohol use is a count variable that we expected to be zeroinflated, we fitted hurdle models with a negative bino- mial distribution for the non-zero counts. These mixture models separately predict (a) the probability that participants drink on any given day and (b) the number of drinks consumed on drinking days. In all models, the day was the unit of analysis. Thus, we predicted alcohol use on a daily level. We fitted these models using the brm function (Bürkner, 2017). In studies where alcohol use was assessed the following day, we reverse-lagged alcohol use so that it lined up with the daily affect assessments. We controlled for day of the week (Monday-Sunday; fixed effect) and time (day in study; fixed effect) in all analyses.

Standardization. Measures of negative and positive affect were person-mean centered and standardized such that each person's daily affect scores reflected departures from their own averages. For example, a score of 1 represents a person reporting affect one standard deviation higher than usual, relative to their own average. Similarly, a score of -1 represents a person reporting affect one SD lower than usual. Just one measure of coping and enhancement motives was available per person, so these scores were sample-mean centered and standardized such that each person's motives scores reflect departures in standard deviation units from the mean of the sample.

Random-effects structure. We built a three-level model of daily observations nested in participants, which were further nested in studies. We fit a random intercept nested within participants to account for differences in drinking frequency and quantity between participants. We further nested these participant-level intercepts within studies to account for differences in drinking frequency and quantity between studies. We fitted a random slope for affect nested in participants and studies to account for variability in the effect of negative and positive affect on drinking between participants and studies. We fitted a random slope for drinking motives as well as the affect $\times$ motives interactions nested in studies only, since motives were measured between participants.

Priors and effect size benchmarks. We used a normally distributed prior with a mean of zero and a standard deviation of 0.5 on all fixed main and interaction effects in the hurdle and negative binomial parts of our models. We consulted with the authorship team to obtain consensus agreements about what effects could represent small, medium, and large effects on daily alcohol use. We preregistered the following conclusions regarding a range of effect sizes along our prior probability distribution: A small effect was defined as any effect smaller than a 1.25 -fold increase in the probability of drinking and a 0.25 increase in number of drinks 
consumed on drinking days as affect increases by one standard deviation. A moderate effect was defined as any effect larger than that, but smaller than a two-fold increase in the probability of drinking as well as an increase of one additional drink consumed on drinking days as affect increases by one standard deviation. Any effect larger than that would be considered a large effect.

Analysis steps. First, we tested the daily effect of negative and positive affect in datasets containing all studies assessing at least two items of the emotion inventory used by Zevon and Tellegen (Zevon \& Tellegen, 1982). We further conducted three sensitivity analyses to determine whether our results were contingent on the particular list of negative and positive affect items used to calculate the daily score. For this reason, we repeated our tests of Hypotheses $1 \mathrm{a}$ and $1 \mathrm{~b}$ using all negative and positive affect items assessed in each respective study, the 10-item negative and positive affect subscales of the PANAS (Watson et al., 1988), as well as the basic negative and positive emotion sub-scales of the PANAS-X (Watson \& Clark, 1994). Next, we repeated the tests of Hypotheses $1 \mathrm{a}$ and $1 \mathrm{~b}$ in a subset of studies which allowed us to temporally dissociate assessments of affect and subsequent alcohol use (i.e., by calculating daily affect from assessments that happened prior to alcohol use). We further tested whether the timing of affect assessment matters by predicting alcohol use from morning $(6 \mathrm{am}-12 \mathrm{pm})$ and afternoon $(12 \mathrm{pm}$ $-6 \mathrm{pm}$ ) affect assessments respectively. We also tested whether between-person differences in affect predict alcohol use by replacing day-level affect scores with person-level affect scores.

Second, we tested interactions between affect and motives in a dataset containing all eligible studies that assessed motives. Third, we further tested whether several moderators influence our conclusions regarding the main effects of affect as well as the cross-level interactions. For these analyses, we added three-level interactions between affect, drinking motives, and the moderator as well as all lower-order interactions to our preregistered models. On a study-level, we tested the moderating influence of study design (diary vs EMA), study population (college vs community vs clinical), whether a study involved a clinical treatment (yes vs no), study inclusion criterion (none or light drinkers vs moderate or heavy drinkers), and study length (number of days of observation). On a participant-level, we tested the moderating influence of self-reported alcohol

\footnotetext{
${ }^{4}$ The output of our model inspections can be found in the supplementary materials https://osf.io/jcr2q/.
}

use at baseline (reported number of drinks during an average week), age, and sex (gender, if sex was not available). Finally, we tested the moderating influence of the time of week (social weekend: Thursday, Friday, Saturday vs remaining weekdays).

For each model, we ran four Markov chain Monte Carlo (MCMC) chains with 3,000 iterations. We inspected model fit using the Rhat statistic, effective sample sizes, trace plots, and posterior predictive checks (Vasishth et al., 2018) ${ }^{4}$. For all models, the combination of diagnostics indicated good model convergence and model fit. As we were not able to impute missing data due to the complexity of our statistical models, we assessed whether missing reports of alcohol use were related to an individual's age or sex as well as the report of affect and alcohol use on the previous day. Pointbiserial and phi correlations indicated that missingness in alcohol use data was not strongly associated with age, sex, and previous day's affect and alcohol use (all correlations $<.1$ ).

\section{Results}

\section{Descriptive statistics}

Across all studies, participants reported consuming at least one alcoholic drink on $31.7 \%$ of days and an average of 4.69 drinks ( $S D=4.56)$ on drinking days. Participants average report of daily negative affect was 13.05 points $(S D=16.18)$ and their average report of daily positive affect was 42.24 points $(S D=23.39)$. The distributions of alcohol use on drinking days, affect, and motives are visualized in Figure 2. The within-person correlation between negative and positive affect was small and negative ( $r=-.09)$. Correlations between participant-aggregated affect, participant-aggregated number of drinks consumed, and drinking motives are visualized in Figure 3.

Main effect of negative affect. We found no evidence for a daily association between negative affect and alcohol use (Hypothesis 1a). On days they experienced higher negative affect (+1 SD), our model estimated participants to be 5-10\% less likely to drink and to consume 0 to 0.02 fewer drinks on drinking days (Figure 4). The authorship team agreed a priori effects of this size are too small to be of practical relevance. A non-preregistered exploratory analysis revealed that negative affect was also not associated with the odds of binge drinking (4+ drinks for women, 5+ drinks for 
men; Centers for Disease Control and Prevention, 2019) on drinking days (95\% CI [0.93, 0.98]).
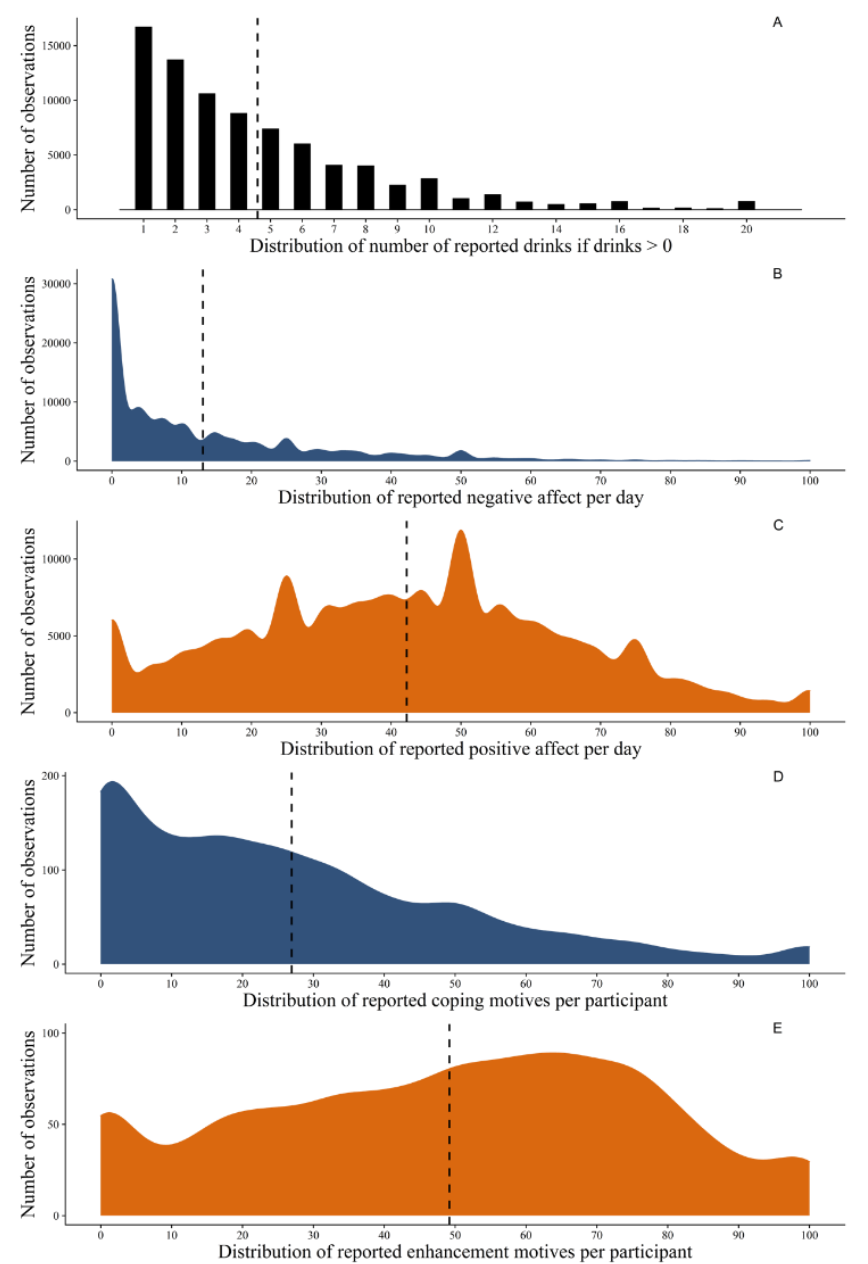

Figure 2. Distributions of study variables. The dashed lines represent the respective mean.

These results were robust across sensitivity analyses (Table 1). First, our conclusions did not change when we calculated negative affect from all negative emotion items in each respective study, when we used the 10item PANAS negative affect subscale, or the fear, hostility, guilt, and sadness subscales from the PANAS-X. Second, our conclusions did not change in a subset of the data in which we were able to temporally dissociate affect and subsequent alcohol use. For this analysis, we predicted alcohol use from affect reports that preceded the onset of drinking. Third, our conclusions did not change when we predicted alcohol use from negative affect reported in the morning or afternoon. Thus, regardless of when or how negative affect was measured, negative affect was not associated with alcohol use on a daily level, and there was minimal heterogeneity in this effect. For more than $99 \%$ of participants, the daily association between negative affect and alcohol use was estimated to be trivially small as indicated by the participant-level random slopes.

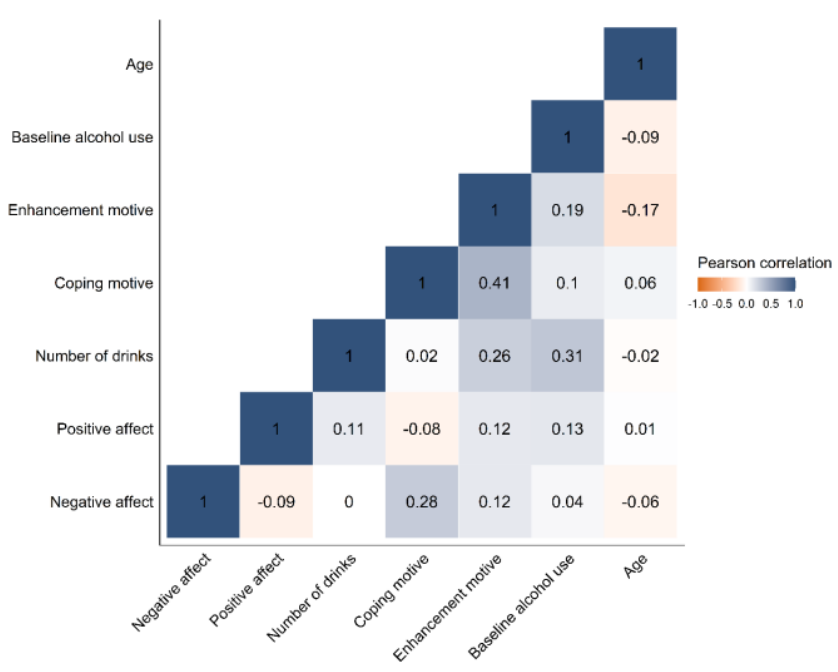

Figure 3. Heat map of correlations between participant-aggregated affect, participant-aggregated number of drinks, drinking motives, self-reported alcohol use at baseline, and age. The values in each tile represent the respective Pearson's correlation coefficient. The magnitude and direction of correlations are visualized with colors.

Main effect of positive affect. In line with Hypothesis $1 \mathrm{~b}$, our model estimated participants to be $16-28 \%$ more likely to drink on days they experience higher positive affect (+1 SD). However, participants were estimated to only consume an additional 0.04 to 0.07 drinks on drinking days high in positive affect (too small to be of relevance according to our preregistered inferences; Figure 5). An exploratory analysis revealed that participants were estimated to be $17-23 \%$ more likely to binge drink on drinking days high in positive affect. Taken together, we conclude from these results that there is evidence in our data for a meaningful small-to-medium sized association between positive affect and both the likelihood to drink and with heavy alcohol use on the daily level.

These results were robust across the same sensitivity analyses as negative affect, except that the effect of the PANAS-X subscale joviality (consisting of the items happy, joyful, delighted, cheerful, excited, enthusiastic, lively, energetic) on the likelihood to drink was slightly larger than our preregistered meta-analytic effect (Table 2). Estimating variability across participants' individual associations between positive affect and alcohol use, roughly two-thirds of participants 
DORA ET AL.

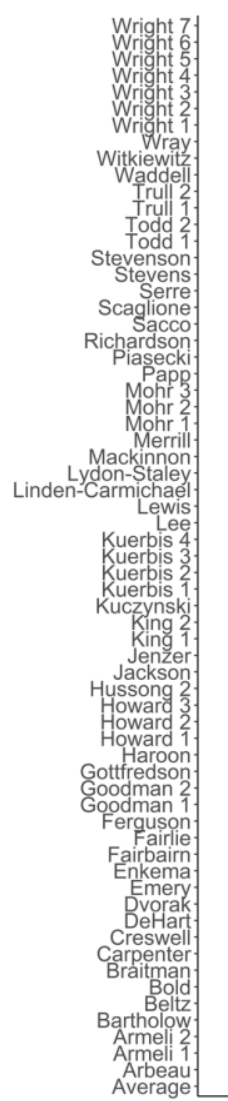

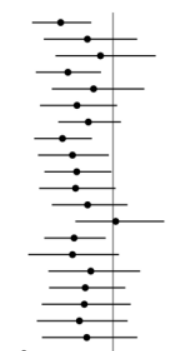

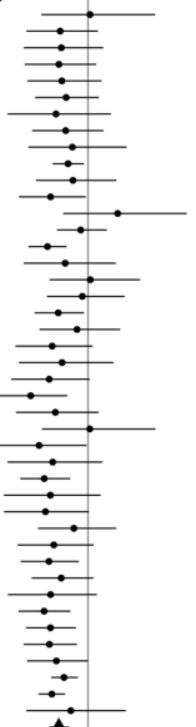

0.5060700 .8091011121314151617181920

1

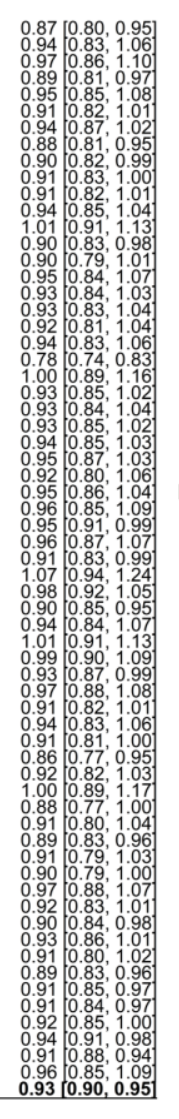

\begin{tabular}{l}
$0.96[0.85,1.099$ \\
$0.93[0.90,0.95$ \\
\hline
\end{tabular}

Effect of negative affect on likelihood to drink

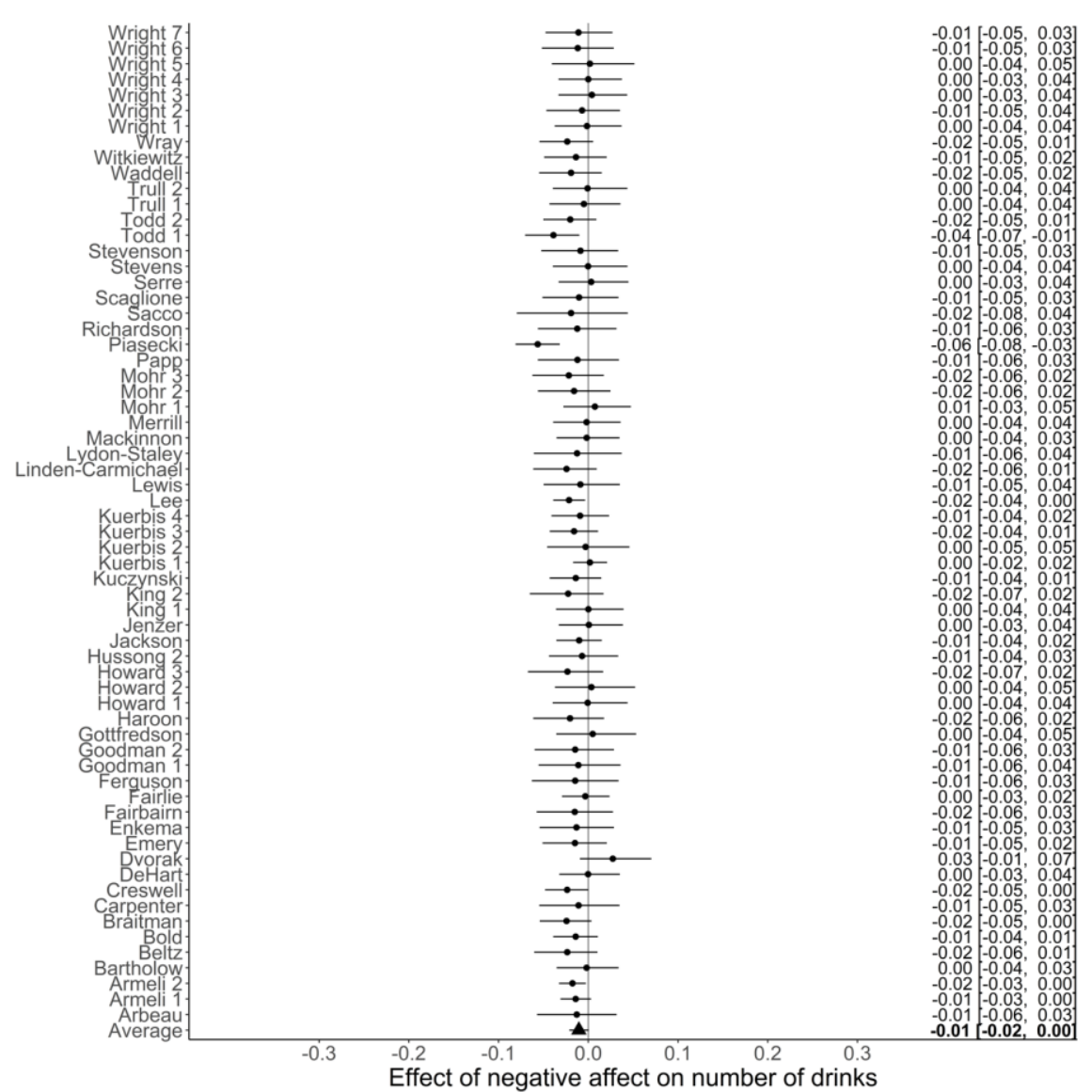

Figure 4. Forest plots of the effect of negative affect on the likelihood to drink with effect sizes larger (smaller) than 1 indicating a higher (lower) probability to drink as affect increases (left) and the number of drinks consumed on drinking days with positive (negative) effect sizes indicating a higher (lower) number of drinks consumed (right). Displayed are point estimates surrounded by the 95\% Bayesian Credible Interval. 
DORA ET AL.

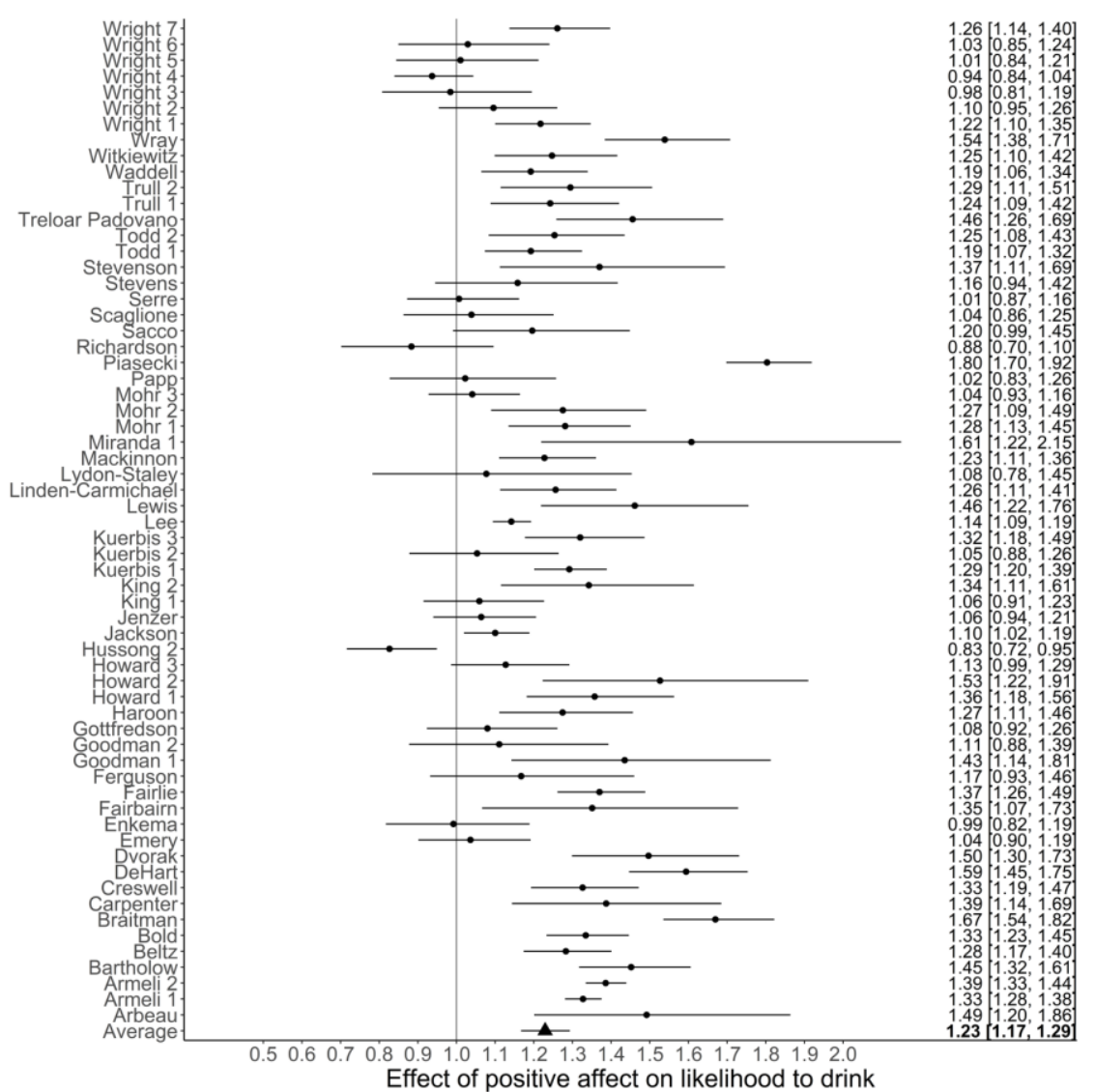

2

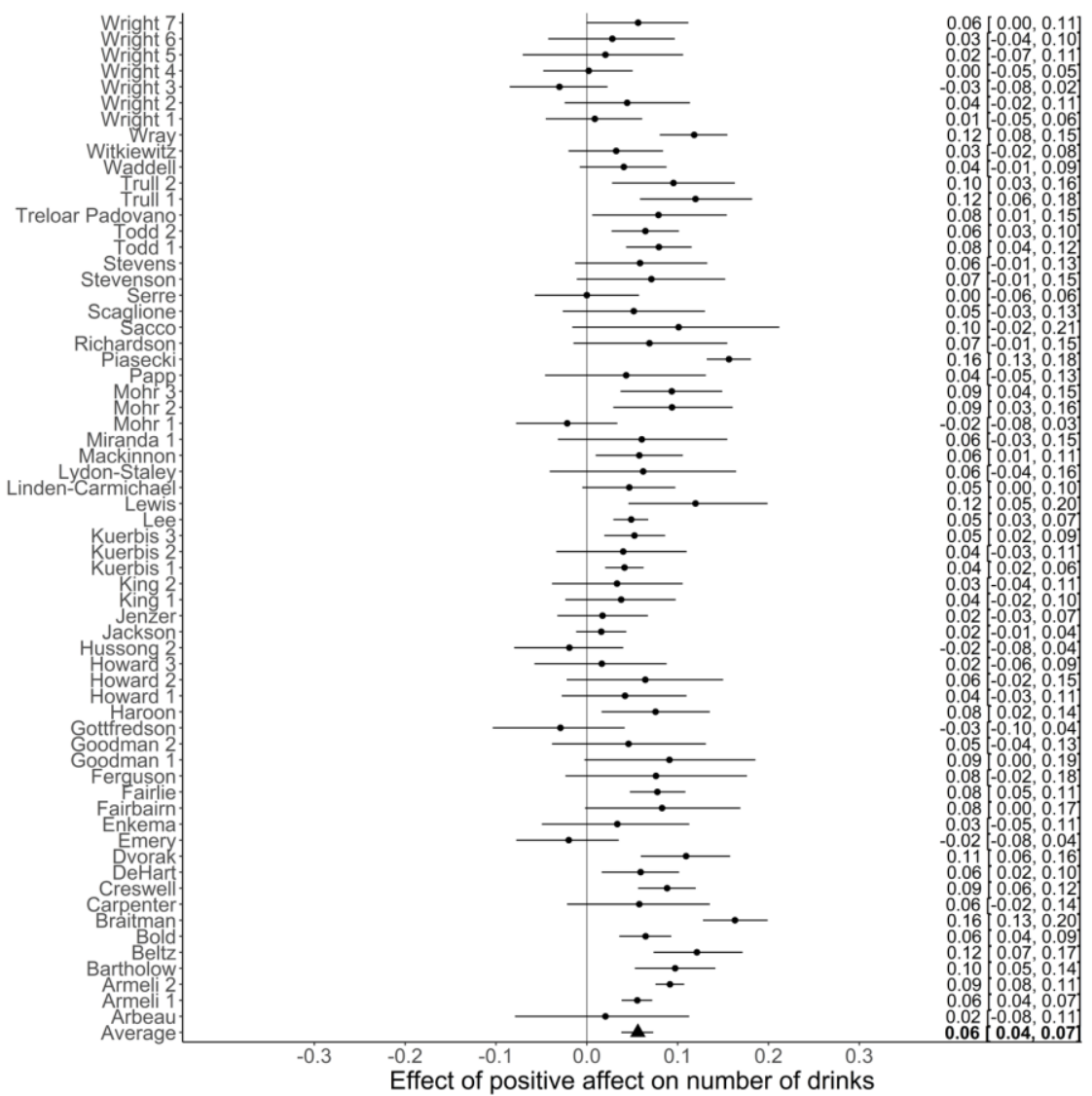

Figure 5. Forest plots of the effect of positive affect on the likelihood to drink with effect sizes larger (smaller) than 1 indicating a higher (lower) probability to drink as affect increases (left) and the number of drinks consumed on drinking days with positive (negative) effect sizes indicating a higher (lower) number of drinks consumed (right). Displayed are point estimates surrounded by the $95 \%$ Bayesian Credible Interval. 
DORA ET AL.

Table 1. Sensitivity analyses for the daily association between negative affect and alcohol use. We report the $95 \%$ credible interval derived from the respective posterior distribution.

\begin{tabular}{|c|c|c|c|c|c|}
\hline \multicolumn{2}{|c|}{ Sensitivity analysis } & \multirow[t]{2}{*}{$k$} & \multirow[t]{2}{*}{$N$} & \multirow{2}{*}{$\begin{array}{l}\text { Likelihood of drinking } \\
95 \% \text { CI }\end{array}$} & \multirow{2}{*}{$\begin{array}{l}\text { Number of drinks consumed } \\
95 \% \text { CI }\end{array}$} \\
\hline & & & & & \\
\hline $\mathrm{NA}_{\text {all items }}$ & $\rightarrow$ alcohol use & 69 & 12,394 & $0.88-0.94$ & $-0.03-0.00$ \\
\hline NAPANAS & $\rightarrow$ alcohol use & 40 & 8,323 & $0.92-0.95$ & $-0.02-0.01$ \\
\hline $\mathrm{NA}_{\text {fear }}$ & $\rightarrow$ alcohol use & 25 & 3,920 & $0.93-0.97$ & $-0.01-0.02$ \\
\hline $\mathrm{NA}_{\text {hostility }}$ & $\rightarrow$ alcohol use & 30 & 5,944 & $0.94-0.99$ & $-0.02-0.02$ \\
\hline $\mathrm{NA}_{\text {guilt }}$ & $\rightarrow$ alcohol use & 20 & 4,971 & $0.93-0.99$ & $-0.02-0.01$ \\
\hline $\mathrm{NA}_{\text {sadness }}$ & $\rightarrow$ alcohol use & 18 & 1,986 & $0.89-0.99$ & $-0.03-0.00$ \\
\hline $\mathrm{NA}_{\text {temporal association }}$ & $\rightarrow$ alcohol use & 32 & 5,957 & $0.90-0.95$ & $-0.02-0.01$ \\
\hline $\mathrm{NA}_{\text {morning }}$ & $\rightarrow$ alcohol use & 29 & 3,430 & $0.93-1.00$ & $-0.02-0.03$ \\
\hline $\mathrm{NA}_{\text {afternoon }}$ & $\rightarrow$ alcohol use & 37 & 5,474 & $0.92-0.97$ & $-0.02-0.00$ \\
\hline $\mathrm{NA}_{\text {person-aggregated }}$ & $\rightarrow$ alcohol use & 64 & 11,869 & $0.74-0.99$ & $0.01-0.17$ \\
\hline $\mathrm{NA}_{\text {within } \times \text { between }}$ & $\rightarrow$ alcohol use & 64 & 11,869 & $0.99-1.03$ & $0.00-0.01$ \\
\hline
\end{tabular}

Notes: $k=$ number of studies included in analysis; $N=$ number of participants included in analysis; NA = negative affect; all items $=$ affect score calculated from all assessed items; PANAS = affect score calculated from PANAS scale items; fear, hostility, guilt, sadness = affect score calculated from PANAS-X subscale items; temporal association $=$ affect score calculated from items assessed prior to alcohol use; morning $=$ affect score calculated from morning $(6 \mathrm{am}-12 \mathrm{pm})$ assessments; afternoon $=$ affect score calculated from afternoon $(12 \mathrm{pm}-6 \mathrm{pm})$ assessments; person-aggregated $=$ affect score aggregated across all study days per participant; within $\times$ between $=$ interaction between within-person and between-person NA (not preregistered).

Table 2. Sensitivity analyses for the daily association between positive affect and alcohol use. We report the $95 \%$ credible interval derived from the respective posterior distribution

\begin{tabular}{|c|c|c|c|c|c|}
\hline \multicolumn{2}{|c|}{ Sensitivity analysis } & $k$ & $N$ & Likelihood of drinking & Number of drinks consumed \\
\hline & & & & $95 \% \mathrm{CI}$ & $95 \% \mathrm{CI}$ \\
\hline $\mathrm{PA}_{\text {all items }}$ & $\rightarrow$ alcohol use & 65 & 11,705 & $1.18-1.30$ & $0.04-0.07$ \\
\hline PAPANAS & $\rightarrow$ alcohol use & 42 & 8,685 & $1.11-1.27$ & $0.02-0.07$ \\
\hline PA $_{\text {joviality }}$ & $\rightarrow$ alcohol use & 55 & 10,708 & $1.27-1.41$ & $0.06-0.11$ \\
\hline $\mathrm{PA}_{\text {self-assurance }}$ & $\rightarrow$ alcohol use & 14 & 1,943 & $1.01-1.20$ & $-0.04-0.05$ \\
\hline PA $_{\text {attentiveness }}$ & $\rightarrow$ alcohol use & 20 & 2,887 & $0.99-1.11$ & $-0.02-0.03$ \\
\hline $\mathrm{PA}_{\text {temporal association }}$ & $\rightarrow$ alcohol use & 31 & 5,857 & $1.15-1.28$ & $0.02-0.06$ \\
\hline $\mathrm{PA}_{\text {morning }}$ & $\rightarrow$ alcohol use & 30 & 3,471 & $1.01-1.14$ & $-0.01-0.05$ \\
\hline $\mathrm{PA}_{\text {afternoon }}$ & $\rightarrow$ alcohol use & 38 & 5,515 & $1.08-1.18$ & $0.02-0.05$ \\
\hline $\mathrm{PA}_{\text {person-aggregated }}$ & $\rightarrow$ alcohol use & 63 & 11,386 & $0.98-1.37$ & $-0.04-0.11$ \\
\hline $\mathrm{PA}_{\text {within } \times \text { between }}$ & $\rightarrow$ alcohol use & 63 & 11,386 & $0.96-1.02$ & $-0.01-0.01$ \\
\hline
\end{tabular}

Notes: $k=$ number of studies included in analysis; $N=$ number of participants included in analysis; NA=negative affect; all items = affect score calculated from all assessed items; PANAS $=$ affect score calculated from PANAS scale items; joviality, self-assurance, attentiveness $=$ affect score calculated from PANAS-X subscale items; temporal association $=$ affect score calculated from items assessed prior to alcohol use; morning = affect score calculated from morning $(6 \mathrm{am}-12 \mathrm{pm})$ assessments; afternoon = affect score calculated from afternoon $(12 \mathrm{pm}-6 \mathrm{pm})$ assessments; person-aggregated $=$ affect score aggregated across all study days per participant; within $\times$ between $=$ interaction between within-person and between-person PA (not preregistered). 
were slightly more likely to drink on days higher in positive affect, whereas for the remaining one-third, the association was estimated to be medium-sized.

Interaction of negative affect and coping motives. Participants reporting higher coping motives were more likely to drink $(95 \%$ CI $[1.03 ; 1.39])$ and to drink more on drinking days (95\% CI [0.05; 0.26]). Contrary to Hypothesis $2 \mathrm{a}$, we found no evidence for a crosslevel interaction between daily negative affect and dispositional drinking motives on daily alcohol use (likelihood of drinking: 95\% CI [1.00, 1.02]; drinks on drinking days: 95\% CI [-0.02, 0.01]; Figure 6). Participants reporting low coping motives (1 SD below the sample mean) were estimated to be $7-10 \%$ less likely to drink and to consume .02-.04 fewer drinks when negative affect increased by one standard deviation. Participants reporting average coping motives were estimated to be $7-9 \%$ less likely to drink and to consume .01-.02 fewer drinks when negative affect increased by one standard deviation. Participants reporting high coping motives ( $1 \mathrm{SD}$ above the sample mean) were estimated to be $6-10 \%$ less likely to drink and to consume $.00-.02$ fewere drinks when negative affect increased by one standard deviation. Thus, we conclude that the daily association between negative affect and alcohol use does not differ as a function of a person's self-reported disposition to drink-to-cope with negative emotions.

Interaction of positive affect and enhancement motives. Participants reporting higher enhancement motives were more likely to drink (95\% CI [1.05; 1.30]) and to drink more on drinking days (95\% CI $[0.21 ; 0.42])$. Contrary to Hypothesis $2 \mathrm{~b}$, we found no evidence for the hypothesized cross-level interaction between daily positive affect and dispositional enhancement motives on daily alcohol use (likelihood of drinking: $95 \%$ CI $[0.93 ; 1.02]$; drinks on drinking days: 95\% CI [-0.02; 0.01]; Figure 6). Participants reporting low enhancement motives (1 SD below the sample mean) were estimated to be $22-32 \%$ more likely to drink and to consume .06-.09 additional drinks when positive affect increased by one standard deviation. Participants reporting average enhancement motives were estimated to be $28-32 \%$ more likely to drink and to consume .06-.07 additional drinks when positive affect increased by one standard deviation. Participants reporting high enhancement motives (1 SD above the sample mean) were estimated to be $28-39 \%$ more likely to drink and to consume $.05-.07$ additional drinks when positive affect increased by one standard deviation. We conclude from these results that the daily association between positive affect and alcohol use does not depend on a person's self-reported disposition to drinkto-enhance positive emotions.

Meta-analytic moderator analyses. In Tables 3 and 4 , we present the results of our moderator analyses for the daily association of negative and positive affect with alcohol use. We present the effect of a 1-SD increase in negative and positive affect on the estimated likelihood to drink and the estimated number of drinks consumed for two to three relevant levels per moderator. These results can be compared to our preregistered effect size benchmarks. The analyses reported in Table 3 highlight that our conclusions for the association between negative affect and drinking do not change along different study designs or for different subpopulations. For example, the estimated effect of negative affect on the likelihood to drink was smaller than our smallest effect size of interest (a $25 \%$ in/decrease in likelihood to drink) in college samples (5-9\% decrease in likelihood to drink as negative affect increased by $1 \mathrm{SD}$ ), community samples (4-11\% decrease in likelihood to drink as negative affect increased by 1 SD), and clinical samples (1-14\% decrease in likelihood to drink as negative affect increased by 1 SD).

Similar to negative affect, our conclusions regarding positive affect did not change along different study designs or for different subpopulations (Table 4). The effect of positive affect on the likelihood to drink hovered around the effect size observed in the main analyses (a 16-28\% increase in the likelihood to drink as positive affect increases by $1 \mathrm{SD}$ ) in all subpopulations we were able to look at, but positive affect was never associated with the number of drinks consumed. For example, a 1-SD increase in positive affect was estimated to lead to a $23-30 \%$ increase in the likelihood to drink in studies that sampled only moderate-to-heavy drinkers, and to a $30-33 \%$ increase in the likelihood to drink in studies that also included light drinkers. 
DORA ET AL.
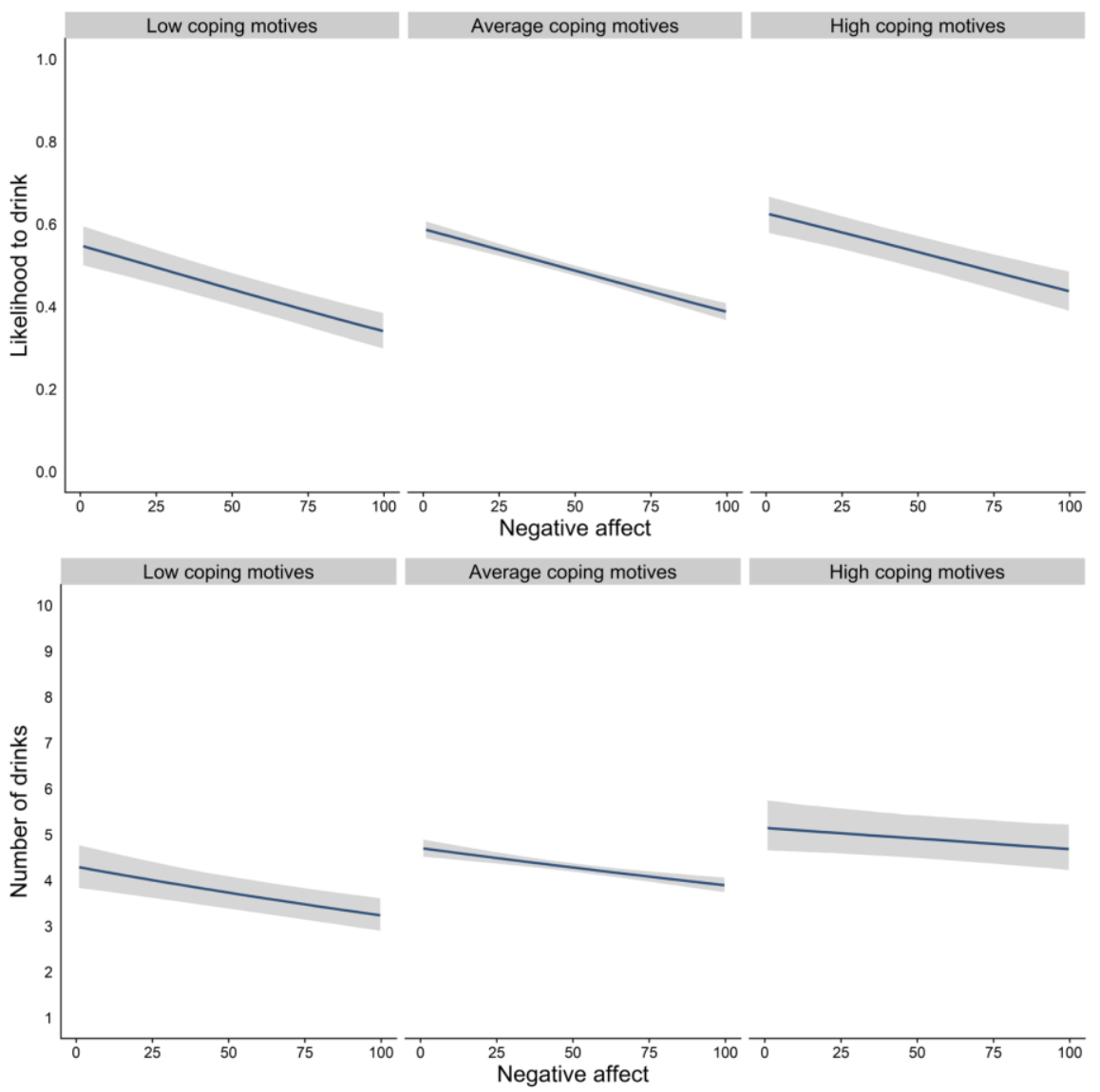
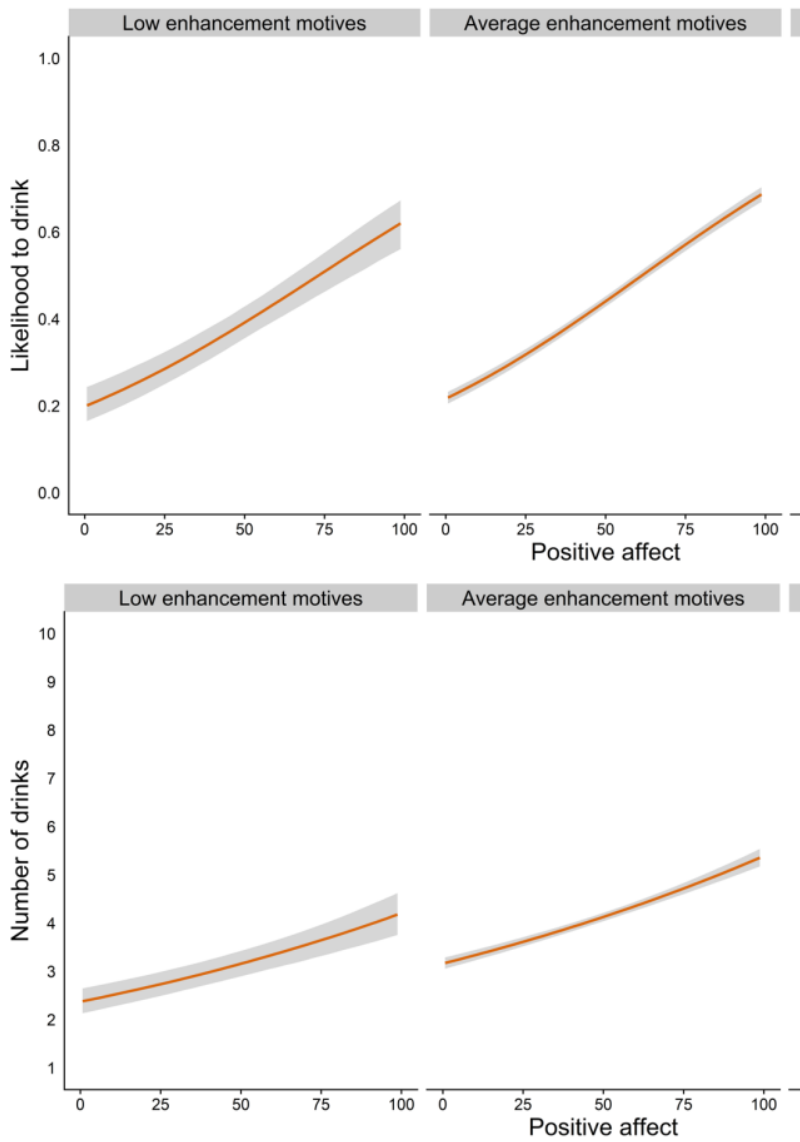

High enhancement motives

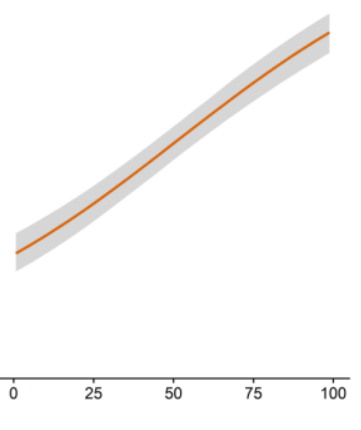

High enhancement motives

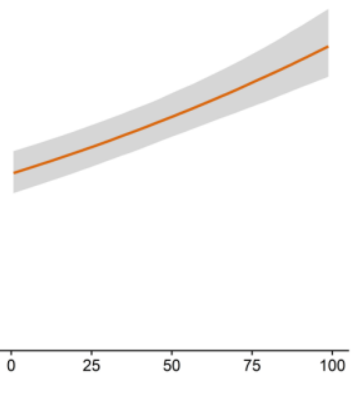

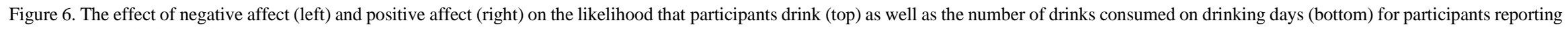
low, average, and high coping and enhancement motives respectively. 
Table 3. Moderator analyses for the daily association between negative affect and alcohol use. We report the 95\% credible interval derived from the respective posterior distribution.

\begin{tabular}{|c|c|c|c|c|}
\hline Moderator analysis & $k$ & $N$ & Likelihood of drinking & Number of drinks \\
\hline & & & $95 \% \mathrm{CI}$ & $95 \% \mathrm{CI}$ \\
\hline \multicolumn{5}{|l|}{ Study design } \\
\hline Diary & 18 & 4451 & $0.92-0.94$ & $-0.02-0.00$ \\
\hline EMA & 25 & 3060 & $0.89-0.93$ & $-0.04--0.02$ \\
\hline \multicolumn{5}{|l|}{ Study population } \\
\hline College & 19 & 4338 & $0.92-0.95$ & $-0.02-0.00$ \\
\hline Community & 18 & 2688 & $0.90-0.96$ & $-0.02-0.01$ \\
\hline Clinical & 6 & 485 & $0.88-0.99$ & $-0.03-0.02$ \\
\hline \multicolumn{5}{|l|}{ Study involving treatment } \\
\hline Yes & 5 & 444 & $0.89-0.95$ & $-0.03--0.01$ \\
\hline No & 37 & 7026 & $0.92-0.93$ & $-0.03-0.00$ \\
\hline \multicolumn{5}{|l|}{ Study inclusion criterion } \\
\hline None/light drinkers & 26 & 5217 & $0.90-0.93$ & $-0.02--0.01$ \\
\hline Moderate/heavy drinkers & 17 & 2294 & $0.90-0.94$ & $-0.03--0.01$ \\
\hline \multicolumn{5}{|l|}{ Study length } \\
\hline Short (-1 SD) & & & $0.89-0.93$ & $-0.03--0.01$ \\
\hline Average & & & $0.92-0.94$ & $-0.02--0.01$ \\
\hline Long (+1 SD) & & & $0.93-0.96$ & $-0.03--0.01$ \\
\hline \multicolumn{5}{|l|}{ Participant self-reported alcohol use } \\
\hline Low (-1 SD) & & & $0.84-0.88$ & $-0.04--0.02$ \\
\hline Average & & & $0.88-0.92$ & $-0.04--0.02$ \\
\hline $\operatorname{High}(+1 \mathrm{SD})$ & & & $0.90-0.96$ & $-0.04--0.02$ \\
\hline \multicolumn{5}{|l|}{ Participant age } \\
\hline Young $(-1$ SD) & & & $0.90-0.93$ & $-0.02--0.01$ \\
\hline Average & & & $0.92-0.93$ & $-0.02--0.01$ \\
\hline Old (+1 SD) & & & $0.92-0.94$ & $-0.03--0.01$ \\
\hline \multicolumn{5}{|l|}{ Participant sex } \\
\hline Female & & 4199 & $0.88-0.93$ & $-0.02--0.01$ \\
\hline Male & & 3254 & $0.93-0.96$ & $-0.03--0.01$ \\
\hline \multicolumn{5}{|l|}{ Time of week } \\
\hline Thursday - Saturday & & & $0.92-0.93$ & $-0.03--0.01$ \\
\hline Sunday - Wednesday & & & $0.90-0.94$ & $-0.03--0.01$ \\
\hline
\end{tabular}


Table 4. Moderator analyses for the daily association between positive affect and alcohol use. We report the 95\% credible interval derived from the respective posterior distribution.

\begin{tabular}{|c|c|c|c|c|}
\hline Moderator analysis & $k$ & $N$ & Likelihood of drinking & Number of drinks \\
\hline & & & $95 \% \mathrm{CI}$ & $95 \% \mathrm{CI}$ \\
\hline \multicolumn{5}{|l|}{ Study design } \\
\hline Diary & 17 & 4390 & $1.28-1.32$ & $0.05-0.07$ \\
\hline EMA & 26 & 3101 & $1.27-1.32$ & $0.06-0.08$ \\
\hline \multicolumn{5}{|l|}{ Study population } \\
\hline College & 18 & 4238 & $1.28-1.32$ & $0.04-0.06$ \\
\hline Community & 20 & 2829 & $1.27-1.32$ & $0.05-0.07$ \\
\hline Clinical & 5 & 424 & $1.19-1.33$ & $0.02-0.07$ \\
\hline \multicolumn{5}{|l|}{ Study involving treatment } \\
\hline Yes & 4 & 383 & $1.25-1.32$ & $0.04-0.08$ \\
\hline No & 38 & 7067 & $1.28-1.32$ & $0.06-0.08$ \\
\hline \multicolumn{5}{|l|}{ Study inclusion criterion } \\
\hline None/light drinkers & 27 & 5329 & $1.30-1.33$ & $0.06-0.08$ \\
\hline Moderate/heavy drinkers & 16 & 2162 & $1.23-1.30$ & $0.05-0.07$ \\
\hline \multicolumn{5}{|l|}{ Study length } \\
\hline Short (-1 SD) & & & $1.28-1.33$ & $0.06-0.08$ \\
\hline Average & & & $1.28-1.32$ & $0.06-0.07$ \\
\hline Long (+1 SD) & & & $1.27-1.32$ & $0.05-0.07$ \\
\hline \multicolumn{5}{|c|}{ Participant self-reported alcohol use } \\
\hline Low (-1 SD) & & & $1.32-1.39$ & $0.09-0.13$ \\
\hline Average & & & $1.30-1.35$ & $0.07-0.09$ \\
\hline $\operatorname{High}(+1 \mathrm{SD})$ & & & $1.27-1.33$ & $0.05-0.08$ \\
\hline \multicolumn{5}{|l|}{ Participant age } \\
\hline Young $(-1 \mathrm{SD})$ & & & $1.30-1.35$ & $0.05-0.06$ \\
\hline Average & & & $1.28-1.32$ & $0.06-0.07$ \\
\hline Old (+1 SD) & & & $1.25-1.30$ & $0.07-0.09$ \\
\hline \multicolumn{5}{|l|}{ Participant sex } \\
\hline Female & & 4205 & $1.32-1.37$ & $0.06-0.08$ \\
\hline Male & & 3227 & $1.23-1.28$ & $0.06-0.07$ \\
\hline \multicolumn{5}{|l|}{ Time of week } \\
\hline Thursday - Saturday & & & $1.27-1.32$ & $0.06-0.08$ \\
\hline Sunday - Wednesday & & & $1.22-1.27$ & $0.07-0.09$ \\
\hline
\end{tabular}




\section{Discussion}

Motivational theories of alcohol use hypothesize that people drink to decrease negative emotions or to increase positive ones (e.g., Baker et al., 2004; Cooper et al., 1995; Cox \& Klinger, 1988; Koob \& Le Moal, 2008). Although supportive evidence has linked affect and alcohol use behaviors using laboratory, experimental, and self-report data (Bresin et al., 2018; Leigh, 1989; Smith, 2013; Wilkie \& Stewart, 2005), two decades of daily diary and EMA studies testing these theories at the day-level produced inconclusive evidence. Using individual participant level data from 69 studies with 12,394 participants and 353,762 days of observations, we showed that people were indeed more likely to drink and to drink heavily on days characterized by positive affect, but they were not more likely to drink or drink more on days characterized by negative affect. Importantly, these findings were consistent across multiple operationalizations of affect, whether or not affect was measured prior to when drinking occurred, and whether affect was assessed in the morning or afternoon. In the available data, the results did not differ between college, community, and clinical samples, nor between heavy and light drinkers. Moreover, people who reported they drink to relieve negative emotions or to enhance positive ones were more likely to drink and to drink more (which mirrors results of a recent metaanalysis in mostly cross-sectional studies; Bresin \& Mekawi, 2021), but did not exhibit any stronger associations between daily affect and drinking.

\section{Implications for motivational models of alcohol use}

The lack of evidence for increased alcohol use on days characterized by higher (preceding) negative affect is striking given the evidence that increased negative affect does precede other risky and unhealthy behaviors. Diary and EMA research on binge eating (Haedt-Matt \& Keel, 2011), smoking (Akbari et al., 2020), and suicidal injury, thoughts, and behaviors (Kuehn et al., 2022) have all demonstrated heightened negative affect prior to engaging in these behaviors. Although alcohol use may be an exception, according to an internal survey among the co-authors of this review conducted during the pre-registration process, 20 out of 38 responding experts expected to find a daily association between negative affect and alcohol use in the present project. Such an effect would have aligned with the subjective priors of the majority of our author team, the global predictions of multiple theoretical models of alcohol use (Cooper et al., 1995; Cox \&
Klinger, 1988), and laypeople's intuitions (Cooper, 1994). Thus, the most important conclusion we can draw from these results is that these priors have now shifted considerably, and we should no longer universally expect people to be more likely to drink or to drink more on days they experience higher negative affect.

Of note, a recent meta-analysis (Tovmasyan et al., 2022) concluded that people drank more on days higher in both negative and positive affect, suggesting that the intensity, rather than the valence, of emotions motivate people to consume alcohol. Although this contrasts with our findings, it is difficult to compare these syntheses of the same literature, because Tovmasyan and colleagues (2022) extracted effects from a smaller number of (mostly) published daily diary and EMA studies ( $k=38$ for NA, $k=35$ for PA), while we obtained individual participant data from a wide range of published and unpublished studies and analyzed data using a unified protocol. Because of the statistical challenges in summarizing associations across such a wide range of measures, outcomes, and analytic methods, we are confident in the robustness of our findings.

Another explanation for our findings could be that alcohol use is more situationally constrained than other behaviors linked to negative affect; people commonly eat and smoke throughout the day and week, whereas people are much more likely to drink alcohol in the evening, on weekends, and while surrounded by other people (Acuff et al., 2021; Arfken, 1988). As such, it is possible that people use other non-alcohol related copings strategies to manage negative affect during the day. Alternately, a negative affect-alcohol association might only be observed when the two occur close in time, rather than when affect is aggregated over the course of a day. There also may be countervailing effects: some occasions of higher than usual negative affect may decrease the likelihood of drinking (e.g., by skipping a social event when feeling down); whereas on other occasions, heightened negative affect may increase the likelihood of turning to alcohol. Overall, this would result in a null effect of negative affect, as observed in this meta-analysis.

Although the notion of drinking to enhance positive affect does not necessarily imply that elevated positive emotions are expected to motivate drinking, we found that people were more likely to drink and to drink heavily on days they felt happy and enthusiastic. It may be that positive affect itself triggers drinking behavior or it may make people more sociable or reward- seeking, increasing the odds that people will seek out situations where alcohol is available (van Hoorn et al., 2016). Al- 
ternatively, perhaps positive affect simply rises in anticipation of drinking events (a "TGIF" effect), which are frequently social in nature.

Contrary to motivational models of alcohol use (Cooper et al., 1995), people's self-reported drinking motives did not moderate individual differences in the association between daily affect and alcohol use. This null effect is consistent with earlier work showing that explicit motives were unrelated to individual differences in affective and drinking processes observed in daily life (Littlefield et al., 2012). Indeed, people's global self-reports of coping strategies are poor markers of how they report coping when measured in the moment (Todd et al., 2004), and people's global selfreports of how they typically respond to negative emotion are not associated with the strength of the same within-person association when measured using EMA (Feil et al., 2020). It may be that a person's self-report of dispositional motives reflects a mental model arising from formative drinking experiences, social cues, and norms around the function of alcohol use, or from selectively recalled drinking events, rather than a description of a typical alcohol decision-making process for that person. Further, people may hold an additional set of implicit drinking motives that lies outside of their awareness (McClelland et al., 1989), which might differ from the drinking motives they report. Recent research has suggested that peoples' daily or momentary coping and enhancement motives for drinking may be robust predictors of same-day emotional drinking (Stevenson et al., 2019; Votaw \& Witkiewitz, 2021). Other cognitive factors, such as cravings (Serre et al., 2015; Waddell et al., 2021), the momentary reinforcement value of alcohol (Acuff et al., 2020; Dora et al., 2022; Murphy \& Mackillop, 2006), other drinking-related cognitions (Lewis et al., 2020), or perceived social support (Shadur et al., 2015) have been shown to vary within-person and may be important for understanding how drinking motives are enacted to influence alcohol use in daily and momentary data.

Our moderator analyses suggest that our findings were consistent across different subpopulations, such as clinical and non-clinical samples, heavy and light drinkers, and younger and older adults. Taken at face value, these results are equally problematic for different affect-regulation models when applied to dailylevel data (e.g., Baker et al., 2004; Cooper et al., 1995; Cox \& Klinger, 1988; Koob \& Le Moal, 2008; Wills \& Filer, 1996), as all models predict negative affect to be associated with alcohol use in at least some of these groups of people. However, given that we had limited data from clinical samples and no direct measure of
AUD symptoms at the participant-level, we have less confidence that our meta-analysis provided a stringent tests of models that focus on people with AUD and/or experiencing withdrawal symptoms (Baker et al., 2004; Koob \& Le Moal, 2008). To us, it remains plausible that daily negative affect predicts drinking in cases of AUD, and especially with individuals with moderate to severe AUD where compulsivity of alcohol use (and the potential for allostatic regulation of drinking) is higher. It is important for future research to test whether there is some threshold in AUD whereby negative affect regulation becomes an important causal mechanism. We also acknowledge that this study and the literature it meta-analyzed has several limitations (e.g., the time scale at which we tested the effects) that prevent us from conclusively falsifying any of the theoretical models, despite the consistencies we found across moderator analyses.

\section{Implications for prevention and treatment}

Motivational models of alcohol use have influenced the design of interventions aimed at problematic drinking in stand-alone treatments (Stasiewicz et al., 2013) and identified potential mechanisms of more generalized treatments aimed at reducing problematic alcohol use in community samples (Kelly et al., 2010; Vinci et al., 2014; Witkiewitz \& Villaroel, 2009). Our results provide evidence that people who report global motives for drinking either for coping or enhancement reasons may benefit from preventive interventions, but global motives do not seem to provide information on how a person's daily alcohol use is influenced by their affective states. In other words, drinking motives may identify who is at risk for problem alcohol use, but they do not yet give us insight into how or when that risk unfolds.

A deeper understanding of why and how positive affect indicates risk for alcohol use (and potentially for heavy alcohol use), and in what contexts, will be important for shaping future interventions. For example, momentary interventions could detect increases in positive affect and deliver reminders of effective protective behavioral strategies that might reduce risk for an upcoming drinking event. On the other hand, preventive interventions targeting days characterized by high negative affect are unlikely to be effective for a typical person. It may instead be important to track momentary drinking motives, people's attributions about their drinking (such as momentary alcohol expectancies), or their situational context (such as being alone vs. with friends Ariss et al., 2022; Creswell, 2021; Fairbairn \& 
Sayette, 2014), which may serve as a more specific signal of risk for alcohol use.

\section{Constraints on generality and study limitations}

The generalizability of our findings regarding the daily association between affect and alcohol use is constrained by several factors such as the people studied, the measurements used, the temporal design and the statistical models used in the current study (Simons, Shoda, \& Lindsay, 2017; Yarkoni, 2020).

Sample generality. First, we limited our systematic search to English terms (and thus potentially excluded non-English literature if it did not appear in our search) and were only able to compile data from mostly young adults and exclusively from Western, predominantly White cultures. Thus, future reviews could include search terms in other languages, and it is an open question whether our data generalize to people living in societies that are not WEIRD (Henrich et al., 2010). Beyond the demographic nature of our sample, relatively few diary or EMA studies of alcohol use involve samples of people seeking treatment for alcohol use disorders (in the present study we had four diary and two EMA studies, total $n=790$ ). This is relatively striking given the emphasis of many affect regulation theories on the role of affect in alcohol use disorders (Koob \& Le Moal, 2008). Thus, our findings may not replicate when examining affect-alcohol associations among individuals with more severe alcohol use disorder than what is typically observed in community samples or among those who are treatment-seeking.

Measurement generality. This study harmonized data coming from dozens of different studies. Although we managed to address some differences between studies (e.g., the items used to calculate negative and positive affect) and tested for others in our moderation analyses, it is not feasible to comprehend the potential impact of an exhaustive list of differences, and we are certain we have not accounted for all of them. For example, one difference between included studies we did not address is the time scale referred to by the affect items (e.g., "right now" vs "the past 30 minutes"). As noted by Curran \& Hussong (2009), the validity of the inferences we wish to draw from this pooled data analysis is directly influenced by the reliability and validity of the measures in each contributing dataset. Pooling across studies using measures of negative and positive affect that differed in terms of the specific items or item responses assumes invariance and comparability of these measures across studies and populations. If this assumption did not hold, our findings may have changed, especially in terms of the heterogeneity of results across studies. More comprehensive data harmonization methods, such as integrative data analysis (Hussong, Curran, \& Bauer, 2013) might be used to combine datasets with similar but varying measures of affect. As such, the possibility remains that some of these unaccounted differences have influenced our results in ways we did not anticipate.

Temporal generality. We tested only the most common formulation of motivational theories of drinking, that daily alcohol use is preceded by increases in negative or positive affect on the same day. As with many vague verbal theories in psychology (van Rooij \& Blokpoel, 2020), motivational theories of alcohol use are silent on the timescale at which these associations are likely to occur, making it difficult to convincingly support or falsify the hypothesis (Hopwood, Bleidorn, \& Wright, 2021). It is entirely possible that the affectalcohol use association varies at longer or shorter time scales. For example, negative affect-motivated drinking may only be observed when affect is measured close in time to drinking events. Alternately, because drinking occasions are often situationally constrained to evenings and weekends, it might be that negative affect experienced earlier in a day or a week has a cascading effect on drinking later in the week once drinking opportunities are more available, mediated by an intention to drink that then persists up to the drinking occasion (and even drives increases in positive mood as drinking is anticipated).

It is also important to note that there are a separate class of theories (many of which draw on the same body of theory described above) that describe how associations between affect (especially symptoms of negative affect-driven disorders such as anxiety and depression) and alcohol use and problems might arise at less proximal time scales (Hussong et al., 2011, 2017; Sher, 1991). One theory, for example, hypothesizes that adolescents who are high on internalizing symptoms gravitate towards substance using peers who provide access and exposure to alcohol use (Hussong et al., 2011; Kaplan et al., 1984). There is robust evidence that people high on emotion-driven impulsivity (Coskunpinar \& Cyders, 2013) are especially likely to develop alcohol use disorder. Other research has suggested that young adults who are prone to symptoms of anxiety and depression drink more and report more symptoms of alcohol use disorder over time (Jackson \& Sher, 2003; King et al., 2020; Kushner et al., 2012), although other research has found the opposite to be true in adolescence (Colder et al., 2017). In other words, the evidence from the present study suggesting no daily association 
between negative emotions and alcohol use does not rule out a role of affect at other time scales or of individual differences in the experience or consequences of negative affect. Moreover, the data here do not speak to the degree to which naturally occurring drinking episodes relieve negative affect or enhance positive affect, which is a key component of affect regulation models. Thus, it is critical to measure affect during and after the drinking episode to fully understand its affect regulation effects. Although fewer daily observational studies have been designed to test the temporal association between alcohol use and subsequent affect, some initial evidence from ecological momentary assessment studies (Russell et al., 2020) as well as evidence from experimental studies performed in the lab (Smith, 2013; Wilkie \& Stewart, 2005) suggests that negative affect is reduced and positive affect is enhanced following alcohol consumption. Given that results from experimental lab studies suggest that people consume more alcohol following negative mood inductions (Bresin et al., 2018), more ecologically valid research is needed where people's affective states are closely and frequently monitored before and during drinking and matching non-drinking episodes.

Statistical generality. Our mixed-effects modeling approach characterized the average or group-level association between daily affect and alcohol use. Thus, we cannot definitively conclude that our findings generalize to any one individual within our sample (Molenaar, 2004). That is, negative affect (and likewise, positive affect or related motives) could prompt alcohol use for some people, some of the time, and in some situations. For example, one individual might regularly drink-to-cope following a frustrating day at work, while another individual might drink-to-cope generally only following more extreme distress (e.g., after losing their job). The nomothetic methods used in this metaanalysis pool estimates across people, time, and situations (e.g., assume ergodicity), and are therefore not equipped to account for potential person-, time-, or situation-specific effects in the affect-alcohol association.

Missing data in EMA research. Like most EMA studies in this field, we did not account for missing observations at the daily level. Although mixed-effects models are robust to data missing on the outcome, observations that are also missing at the predictor level are listwise deleted, and the complexities of imputing zero-inflated count variables for our Bayesian mixed effects models precluded the use of multiple imputation. Although we did not find correlates of missingness in our data, it is a possibility that participants sys- tematically missed EMA surveys, which would bias estimates in the current study. For example, people might be less likely to complete a morning survey following a heavy drinking event, or might be less likely to complete a survey in moments of high negative affect. It is important to note, however, that no research has reported that this is true in EMA studies of alcohol use, and one recent study found no evidence that missing data in EMA research was a function of the constructs of interest (Sun et al., 2021). Nonetheless, the question of how missing data impacts reliability of EMA research is a methodological question, requiring additional research to understand systematically the circumstances and study designs that promote high rates of compliance and high-quality data (Kaurin et al., 2022). A promising avenue for future research might be to infer affective states from passive smartphone data via machine learning, which has the advantage that no active responding from the participant is required (Mohr et al., 2017). A recent study had moderate success predicting states of elevated anger and anxiety in this way (Ren et al., 2022). Should the prediction accuracy of these methods increase further, this would be one way to capture moments high in negative affect more reliably in people's everyday life.

\section{An agenda for future research}

Important questions remain regarding whether, in what way, in what contexts, and for whom affect is related to alcohol use in everyday life. It is our hope that this meta-analysis will launch new intensive longitudinal work that pushes beyond our current understanding of the complex real-time relationship between affect and alcohol. To this end, we offer four points that we see as particularly important for future research to address.

First, our tests demonstrating that daily alcohol use is not preceded by daily increases in negative affect tell us little about whether the affect-alcohol use association varies (nonlinearly) at longer or shorter time scales. The present findings challenge the field to improve the precision of the theoretical predictions pertaining to the temporal relationship between affect and alcohol use (Hopwood et al., 2021). Motivational models were originally developed when coarser cross-sectional and years-long longitudinal studies were predominant study designs. Although this field of study has taken advantage of modern data collection tools such as smartphones for real-time survey data collection, theoretical predictions have not been updated in 
concert. We propose further examinations of the associations between affect and drinking using methods that assess affect with greater temporal granularity and with greater proximity to drinking episodes to examine how affect dynamics prompt a drinking response or interact with biphasic effects of alcohol over time.

Second, at least some motivational models of alcohol use (Baker et al., 2004; Koob \& Le Moal, 2008) hypothesize that negative affect is an index of withdrawal symptoms that emerges in the development of substance use disorder. Yet as noted above, there remains a marked disconnect between these theoretical models and the samples with data available to test them. It is unclear to what extent participants in the majority of college student and community samples analyzed here ever experienced true withdrawal symptoms or serious and impairing negative consequences from their alcohol consumption (Boness et al., 2016). We therefore contend that it is critical to invest more resources in understanding the role of emotion dynamics among those in various stages of alcohol use disorder and among those either in treatment or similar, sustained self-directed efforts to reduce drinking.

Relatedly, reports of negative affect at the high end of the scale were extremely rare (scores higher than 70 on a 100-point scale made up less than $1 \%$ of the available negative affect scores), and thus a floor effect may contribute to the observed null results. Given that the current study includes data from 12,394 people measured across over 353,762 days, we believe this represents the typical experience of negative affect in people's daily lives: it tends to be relatively unusual. This is consistent with prior research indicating that the frequency and intensity of positive affect is much higher than negative affect in people's daily lives (Trampe et al., 2015; Watson, 2000; Zelenski \& Larsen, 2000), even in clinical samples (Cho et al., 2017). Even though average negative affect tends to be relatively low even in clinical samples, the meta-analysis by Cho and colleagues (2017) found that negative affect was elevated in clinical samples compared to controls. This further reinforces the need to study affect regulation and drinking motives in everyday life of people with symptoms of alcohol use disorder as the influence of floor effects of negative affect in these samples might be smaller. At the same time, if people were to drink-to-cope only when their experience of negative affect is maximal, these infrequent instances might not be captured by daily observational studies, but rare yet highly salient events may be enough to shape people's perceptions of their drinking behaviors. For example, epidemiological studies consistently indicate co-morbidity between social anxiety disorders and alcohol use disorders (Morris et al., 2005), which might indicate that people use alcohol as a coping strategy in highly distressing moments.

Third, we believe it is time to pay more attention to the immediate context in which emotions are experienced and alcohol is consumed. It is possible that daily studies such as the ones analyzed here obscure a true association between negative affect and alcohol use by ignoring situational constraints and opportunities. For example, suppose one's intention to drink increases immediately following a negative emotional experience, but due to responsibilities or a lack of drinking opportunity this intention is not enacted or is enacted upon delay. We recommend that future studies attempt to capture contextual variables which may help to further characterize the association between affect and alcohol use, such as social context (Creswell, 2021; DeHart et al., 2009), next-day responsibilities, availability of alcohol-free reinforcers in the environment, and types of stressors increasing negative affect. The challenge, of course, is that these factors are essentially limitless and there is a point at which the meaningfulness of an effect would become unclear (e.g., negative affect is associated with alcohol use, but only when a person plans to drink, and is watching TV at home alone on a Friday).

Fourth, negative affect may drive alcohol use for some people, some of the time, at a rate too infrequent to support detection via the modeling approach we and the studies reviewed here chose. As such, the heterogeneity seen in previous examinations of the affect-alcohol use association may be an artifact of the methods used (i.e., nomothetic, mixed-effects models) which examine the average effect and the amount of average variation around the focal effect. As detailed above, the association between affect and alcohol use may vary by person, temporal, and situational factors; and, additionally, all may vary over time. Adequate characterization of these effects and heterogeneity around these effects requires the use of multivariate models equipped to model both average and person-specific effects over time (Litt et al., 2020). Use of such idiographic techniques has been initially useful (Foster \& Beltz, 2021; Wright \& Woods, 2020) and may assist with developing more precise theories, as well as more effective prevention and intervention efforts delivered in the moment and on the individual level over time (Piccirillo \& Rodebaugh, 2019). 


\section{Conclusions}

In conclusion, the findings of this meta-analysis suggest that positive, but not negative affect is associated with alcohol use in daily data in mostly non-clinical samples. These findings stand in contrast to theoretical models which state that negative affect, in particular, is a key drinking motivator, particularly for problematic drinking (Baker et al., 2004; Cloninger, 1987;
Koob \& Le Moal, 2008). Using the insights gained from this meta-analysis, we propose an agenda for future research to explore temporal, contextual, situational, and person-specific aspects of the affect-regulation process of alcohol use to advance theory and improve upon prevention and intervention efforts. 


\section{References}

Acuff, S., Amlung, M., Dennhardt, A., Mackillop, J., \& Murphy, J. (2020). Experimental manipulations of behavioral economic demand for addictive commodities: A meta-analysis. Addiction, $\quad$ 115, 817-831. https://doi.org/10.1111/add.14865

Acuff, S., Stoops, W., \& Strickland, J. (2021). Behavioral economics and the aggregate versus proximal impact of sociality on heavy drinking. Drug and Alcohol Dependence. https://doi.org/10.1016/j.drugalcdep.2021.108523

Akbari, M., Hasani, J., \& Seydavi, M. (2020). Negative affect among daily smokers: A systematic review and meta-analysis. Journal of Affective Disorders, $\quad 274, \quad 553-567$. https://doi.org/10.1016/j.jad.2020.05.063

Aldridge-Gerry, A., Roesch, S., Villodas, F., McCabe, C., \& Leung, Q. (2011). Daily Stress and Alcohol Consumption: Modeling Between-Person and Within-Person Ethnic Variation in Coping Behavior. Journal of Studies on Alcohol and Drugs, $\quad 72, \quad 125-134$. https://doi.org/10.15288/jsad.2011.72.125
American Psychiatric Association. (2013). Diagnostic and statistical manual of mental disorders (5th ed.). American Psychiatric Publishing.

Arbeau, K., Kuiken, D., \& Wild, C. (2011). Drinking to enhance and to cope: A daily process study of motive specificity. Addictive Behaviors, 36, $1174-1183$.

https://doi.org/10.1016/j.addbeh.2011.07.020

Arfken, C. (1988). Temporal pattern of alcohol consumption in the United States. Alcoholism: Clinical and Experimental Research, 12, 137142. https://doi.org/10.1111/j.15300277.1988.tb00147.x

Ariss, T., Fairbairn, C., Sayette, M., Velia, B., Berenbaum, H., \& Brown-Schmidt, S. (2022). Where to look? Alcohol, affect, and gaze behavior during a virtual social interaction. Clinical Psychological Science.

Armeli, S., Tennen, H., Affleck, G., \& Kranzler, H. (2000). Does affect mediate the association between daily events and alcohol use? Journal of Studies on Alcohol, 61, 862-871. https://doi.org/10.15288/jsa.2000.61.862 
Armeli, S., Todd, M., Conner, T., \& Tennen, H. (2008). Drinking to Cope With Negative Moods and the Immediacy of Drinking Within the Weekly Cycle Among College Students. Journal of Studies on Alcohol and Drugs, 69, 313-322. https://doi.org/10.15288/jsad.2008.69.313

Bacon, A., Cranford, A., \& Blumenthal, H. (2015). Effects of Ostracism and Sex on Alcohol Consumption in a Clinical Laboratory Setting. Psychology of Addictive Behaviors, 29, 664-672. https://doi.org/10.1037/adb0000054

Baker, T., Piper, M., McCarthy, D., Majeskie, M., \& Fiore, M. (2004). Addiction motivation reformulated: An affective processing model of negative reinforcement. Psychological Review, 111, 33-51. https://doi.org/10.1037/0033295X.111.1.33

Bold, K., Fucito, L., DeMartini, K., Leeman, R., Kranzler, H., Corbin, W., \& O’Malley, S. (2017). Urgency traits moderate daily relations between affect and drinking to intoxication among young adults. Drug and Alcohol Dependence, $\quad 170, \quad 59-65$. https://doi.org/10.1016/j.drugalcdep.2016.10.035
Boness, C., Lane, S., \& Sher, K. (2016). Assessment of Withdrawal and Hangover is Confounded in the Alcohol Use Disorder and Associated Disabilities Interview Schedule: Withdrawal Prevalence is Likely Inflated. Alcoholism: Clinical and Experimental Research, 40, 1691-1699. https://doi.org/10.1111/acer.13121

Bresin, K., \& Fairbairn, C. (2019). The Association Between Negative and Positive Affect and Alcohol Use:An Ambulatory Study. Journal of Studies on Alcohol and Drugs, 80, 614-622. https://doi.org/10.15288/jsad.2019.80.614

Bresin, K., \& Mekawi, Y. (2021). The "Why" of Drinking Matters: A Meta-Analysis of the Association Between Drinking Motives and Drinking Outcomes. Alcoholism: Clinical and Experimental Research, $\quad 45, \quad 38-50$. https://doi.org/10.1111/acer.14518

Bresin, K., Mekawi, Y., \& Verona, E. (2018a). The effect of laboratory manipulations of negative affect on alcohol craving and use: A meta-analysis. Psychology of Addictive Behaviors, 32, 617-627. https://doi.org/10.1037/adb0000383 
Bresin, K., Mekawi, Y., \& Verona, E. (2018b). The effect of laboratory manipulations of negative affect on alcohol craving and use: A meta-analysis. Psychology of Addictive Behaviors, 32, 617-627. https://doi.org/10.1037/adb0000383

Bürkner, P. (2017). brms: An R Package for Bayesian Multilevel Models Using Stan. Journal of Statistical Software, $\quad 80, \quad 1-28$. https://doi.org/10.18637/jss.v080.i01

Carver, C., Scheier, M., \& Weintraub, J. (1989). Assessing coping strategies: A theoretically based approach. Journal of Personality and Social Psychology, $\quad 56, \quad 267-283$. https://doi.org/10.1037/0022-3514.56.2.267

Centers for Disease Control and Prevention. (2018). National Health Interview Survey-Adult Alcohol Use Information. https://www.cdc.gov/nchs/nhis/alcohol/alcohol_glossary.htm

Centers for Disease Control and Prevention. (2019). What is excessive alcohol use? https://www.cdc.gov/alcohol/onlinemedia/infographics/excessive-alcohol-use.html
Cho, H., Gonzalez, R., Lavaysse, L., Pence, S., Fulford, D., \& Gard, D. (2017). Do people with schizophrenia experience more negative emotion and less positive emotion in their daily lives? A meta-analysis of experience sampling studies. Schizophrenia Research, 183, 49-55. https://doi.org/10.1016/j.schres.2016.11.016

Cloninger, R. (1987). Neurogenetic adaptive mechanism in alcoholism. Science, 236, 410-416. https://doi.org/10.1126/science.2882604

Cohen, P., Cohen, J., Aiken, L., \& West, S. (1999). The Problem of Units and the Circumstance for POMP. Multivariate Behavioral Research, 34, 315-346.

https://doi.org/10.1207/S15327906MBR3403 $-2$

Colder, C. R., Shyhalla, K., Frndak, S., Read, J. P., Lengua, L. J., Hawk, L. W., \& Wieczorek, W. F. (2017). The Prospective Association Between Internalizing Symptoms and Adolescent Alcohol Involvement and the Moderating Role of Age and Externalizing Symptoms. Alcoholism: Clinical and Experimental Research, 41(12), 2185-2196. https://doi.org/10.1111/acer.13512 
Collins, L., Morsheimer, E., Shiffman, S., Paty, J., \& Gnys, M. (1998). Ecological Momentary Assessment in a Behavioral Drinking Moderation Training Program. Experimental Clinical Psychopharmacology, $\quad 6, \quad 306-315$. https://doi.org/10.1037/1064-1297.6.3.306

Collins, R. L., Parks, G. A., \& Marlatt, G. A. (1985). Social determinants of alcohol consumption: The effects of social interaction and model status on the self-administration of alcohol. Journal of Consulting and Clinical Psychology, 53(2), 189-200. https://doi.org/10.1037/0022006X.53.2.189

Conger, J. (1956). Reinforcement Theory and the Dynamics of Alcoholism. Quarterly Journal of Studies on Alcohol, 17, 296-305. https://doi.org/10.15288/qjsa.1956.17.296

Cooper, H., \& Patall, E. (2009). The Relative Benefits of Meta-Analysis Conducted With Individual Participant Data Versus Aggregated Data. Psychological Methods, 14, 165-176. https://doi.org/10.1037/a0015565
Cooper, M. (1994). Motivations for alcohol use among adolescents: Development and validation of a four-factor model. Psychological Assessment, 6, 117-128. https://doi.org/10.1037/10403590.6.2.117

Cooper, M., Frone, M., Russell, M., \& Mudar, P. (1995). Drinking to Regulate Positive and Negative Emotions: A Motivational Model of Alcohol Use. Journal of Personality and Social Psychology, $\quad$ 69, 990-1005. https://doi.org/10.1037/0022-3514.69.5.990

Coskunpinar, A., \& Cyders, M. A. (2013). Impulsivity and substance-related attentional bias: A metaanalytic review. Drug and Alcohol Dependence, $\quad 133(1), \quad 1-14$. https://doi.org/10.1016/j.drugalcdep.2013.05.008

Courtney, J., \& Russell, M. (2021). Testing affect regulation models of drinking prior to and after drinking initiation using ecological momentary assessment. Psychology of Addictive Behaviors, $\quad$ 59, 597-608. https://doi.org/10.1037/adb0000763 
Cox, M., \& Klinger, E. (1988). A Motivational Model of Alcohol Use. Journal of Abnormal Psychology, $\quad 97, \quad$ 168-180. https://doi.org/10.1037/0021-843X.97.2.168

Creswell, K. (2021). Drinking together and drinking alone: A social-contextual framework for examining alcohol use disorder risk. Current $\mathrm{Di}$ rections in Psychological Science, 30.

Curran, P. J., \& Hussong, A. M. (2009). Integrative data analysis: The simultaneous analysis of multiple data sets. Psychological Methods, 14(2), $81-100$ https://doi.org/10.1037/a0015914

de Wit, H., Soderpalm, A., Nikolayev, L., \& Young, E. (2003). Effects of Acute Social Stress on Alcohol Consumption in Healthy Subjects. Alcoholism: Clinical and Experimental Research, 27, $1270-1277$. https://doi.org/10.1097/01.ALC.0000081617. 37539.D6
DeHart, T., Tennen, H., Armeli, S., Todd, M., \& Mohr, C. (2009). A diary study of implicit self-esteem, interpersonal interactions and alcohol consumption in college students. Journal of Experimental Social Psychology, 45(4), 720730.

https://doi.org/10.1016/j.jesp.2009.04.001

Dora, J., Schultz, M., Kuczynski, A., Acuff, S., Murphy, J., \& King, K. (2022). An experimental investigation into the effect of negative affect on the behavioral economic demand for alcohol. Psychology of Addictive Behaviors.

Dora, J., Schultz, M., Shoda, Y., Lee, C., \& King, K. (2022). No evidence for trait- and state-level urgency moderating the daily association between negative affect and subsequent alcohol use in two college samples. Brain and Neuroscience Advances.

Duif, M., Thewissen, V., Wouters, S., Lechner, L., \& Jacobs, N. (2020). Associations between affect and alcohol consumption in adults: An ecological momentary assessment study. The American Journal of Drug and Alcohol Abuse, 46, 88-97.

https://doi.org/10.1080/00952990.2019.16356 
Dvorak, R., Pearson, M., \& Day, A. (2014). Ecological Momentary Assessment of Acute Alcohol Use Disorder Symptoms: Associations With Mood, Motives, and Use on Planned Drinking Days. Experimental Clinical Psychopharmacology, 22, 285-297.

https://doi.org/10.1037/a0037157

Dvorak, R., \& Simons, J. (2014). Daily Associations Between Anxiety and Alcohol Use: Variation by Sustained Attention, Set Shifting, and Gender. Psychology of Addictive Behaviors, 28, 969-979. https://doi.org/10.1037/a0037642

Ehrenberg, E., Armeli, S., Howland, M., \& Tennen, H. (2016). A Daily Process Examination of Episode-Specific Drinking to Cope Motivation among College Students. Addictive Behaviors, 57, 69-75. https://doi.org/10.1016/j.addbeh.2016.02.003

Emery, N., \& Simons, J. (2020). The role of affect, emotion management, and attentional bias in young adult drinking: An experience sampling study. Psychopharmacology, 237, 1557-1575. https://doi.org/10.1007/s00213-020-05480-S
Fairbairn, C. E., \& Sayette, M. A. (2014). A social-attributional analysis of alcohol response. Psychological Bulletin, 140(5), 1361-1382. https://doi.org/10.1037/a0037563

Feil, M., Halvorson, M., Lengua, L., \& King, K. (2020). A state model of negative urgency: Do momentary reports of emotional impulsivity reflect global self-report? Journal of Research in Personality, $\quad 86$. https://doi.org/10.1016/j.jrp.2020.103942

Finlay, A., Ram, N., Maggs, J., \& Caldwell, L. (2012). Leisure Activities, the Social Weekend, and Alcohol Use: Evidence From a Daily Study of First-Year College Students. Journal of Studies on Alcohol and Drugs, 73, 250-259. https://doi.org/10.15288/jsad.2012.73.250

Foster, K., \& Beltz, A. (2021). Heterogeneity in affective complexity among men and women. Emotion.

Gautreau, C., Sherry, S., Battista, S., Goldstein, A., \& Stewart, S. (2015). Enhancement motives moderate the relationship between higharousal positive moods and drinking quantity: Evidence from a 22-day experience sampling study. Drug and Alcohol Review, 34, 595-602. https://doi.org/10.1111/dar.12235 
Gelman, A., \& Loken, E. (2013). The garden of forking paths: Why multiple comparisons can be a problem, even when there is no "fishing expedition" or "p-hacking" and the research hypothesis was posited ahead of time. Department of Statistics, Columbia University.

Gottfredson, N., \& Hussong, A. (2013). Drinking to Dampen Affect Variability: Findings From a College Student Sample. Journal of Studies on Alcohol and Drugs, 74, 576-583. https://doi.org/10.15288/jsad.2013.74.576

Grant, V., Stewart, S., \& Mohr, C. (2009). CopingAnxiety and Coping-Depression Motives Predict Different Daily Mood-Drinking Relationships. Psychology of Addictive Behaviors, 23, 226-237. https://doi.org/10.1037/a0015006

Gray, J. (1982). The neuropsychology of anxiety: An enquiry into the functions of the septo-hippocampal system. Oxford University Press.

Haedt-Matt, A., \& Keel, P. (2011). Revisiting the affect regulation model of binge eating: A meta-analysis of studies using ecological momentary assessment. Psychological Bulletin, 137, 660681. https://doi.org/10.1037/a0023660
Harder, V. S., Ayer, L. A., Rose, G. L., Naylor, M. R., \& Helzer, J. E. (2014). Alcohol, Moods and Male-Female Differences: Daily Interactive Voice Response over 6 Months. Alcohol and Alcoholism, $\quad 49(1), \quad 60-65$. https://doi.org/10.1093/alcalc/agt069

Hawkins, R., \& Clement, P. (1984). Binge eating: Measurement problems and a conceptual model. In The binge purge syndrome: Diagnosis, treatment, and research (pp. 229-251). Springer.

Henrich, J., Heine, S., \& Norenzayan, A. (2010). The weirdest people in the world? Behavioral and Brain Sciences, 33, 61-83. https://doi.org/10.1017/S0140525X0999152X

Hoeppner, B. B., Stout, R. L., Jackson, K. M., \& Barnett, N. P. (2010). How good is fine-grained Timeline Follow-back data? Comparing 30day TLFB and repeated 7-day TLFB alcohol consumption reports on the person and daily level. Addictive Behaviors, 35(12), 11381143. https://doi.org/10.1016/j.addbeh.2010.08.013 
Hopwood, C., Bleidorn, W., \& Wright, A. (2021). Connecting theory to methods in longitudinal research. Perspectives on Psychological Science, $17, \quad 884-894$. https://doi.org/10.1177\%2F174569162110084 07

Howard, A., Patrick, M., \& Maggs, J. (2015). College Student Affect and Heavy Drinking: Variable Associations Across Days, Semesters, and People. Psychology of Addictive Behaviors, 29, 430-443. https://doi.org/10.1037/adb0000023

Hussong, A. (2007). Predictors of drinking immediacy following daily sadness: An application of survival analysis to experience sampling data. $A d$ dictive Behaviors, 32, 1054-1065. https://doi.org/10.1016/j.addbeh.2006.07.011

Hussong, A., Curran, P., \& Bauer, D. (2013). Integrative data analysis in clinical psychology research. Annual Review of Clinical Psychology, 9, 61-89. https://doi.org/10.1146/annurevclinpsy-050212-185522
Hussong, A., Ennett, S., Cox, M., \& Haroon, M. (2017). A Systematic Review of the Unique Prospective Association of Negative Affect Symptoms and Adolescent Substance Use Controlling for Externalizing Symptoms. Psychology of Addictive Behaviors, 31(2), 137147. https://doi.org/10.1037/adb0000247

Hussong, A., Galloway, C., \& Feagans, L. (2005). Coping Motives as a Moderator of Daily MoodDrinking Covariation. Journal of Studies on Alcohol, $\quad 66, \quad 344-353$. https://doi.org/10.15288/jsa.2005.66.344

Hussong, A., Jones, D., Stein, G., Baucom, D., \& Boeding, S. (2011). An Internalizing Pathway to Alcohol Use and Disorder. Psychology of Addictive Behaviors, 25(3), 390-404. https://doi.org/10.1037/a0024519

Jackson, K. M., \& Sher, K. J. (2003). Alcohol Use Disorders and Psychological Distress: A Prospective State-Trait Analysis. Journal of Abnormal Psychology, 112(4), 599-613. https://doi.org/10.1037/0021-843X.112.4.599 
Jahng, S., Solhan, M., Tomko, R., Wood, P., Piasecki, T., \& Trull, T. (2011). Affect and alcohol use: An ecological momentary assessment study of outpatients with borderline personality disorder. Journal of Abnormal Psychology, 120, 572-584. https://doi.org/10.1037/a0024686

Kaplan, H. B., Martin, S. S., \& Robbins, C. (1984). Pathways to Adolescent Drug Use: Self-Derogation, Peer Influence, Weakening of Social Controls, and Early Substance Use. Journal of Health and Social Behavior, 25(3), 270. https://doi.org/10.2307/2136425

Kaurin, A., King, K. M., \& Wright, A. G. C. (2022). Studying Personality Pathology with Ecological Momentary Assessment: Harmonizing Theory and Method [Preprint]. PsyArXiv. https://doi.org/10.31234/osf.io/chszq

Kelly, J., Stout, R., Tonigan, S., Magill, M., \& Pagano, M. (2010). Negative Affect, Relapse, and Alcoholics Anonymous (AA): Does AA Work by Reducing Anger? Journal of Studies on Alcohol and Drugs, 71, 434-444. https://doi.org/10.15288/jsad.2010.71.434
King, K., Feil, M., Halvorson, M., Kosterman, R., Bailey, J., \& Hawkins, D. (2020). A Trait-Like Propensity to Experience Internalizing Symptoms Is Associated With Problem Alcohol Involvement Across Adulthood, but Not Adolescence. Psychology of Addictive Behaviors. https://doi.org/10.1037/adb0000589

Koob, G., \& Le Moal, M. (2008). Addiction and the Brain Antireward System. Annual Review of Psychology, $\quad 59, \quad 29-53$. https://doi.org/10.1146/annurev.psych.59.103006.093548

Kuehn, K., Dora, J., Harned, M., Foster, K., Song, F., Smith, M., \& King, K. (2022). A meta-analysis on the affect regulation function of real-time self-injurious thoughts and behaviours. Nature Human Behaviour. https://doi.org/10.1038/s41562-022-01340-8 
Kushner, M. G., Wall, M. M., Krueger, R. F., Sher, K. J., Maurer, E., Thuras, P., \& Lee, S. (2012). Alcohol Dependence is Related to Overall Internalizing Psychopathology Load Rather than to Particular Internalizing Disorders: Evidence from a National Sample: ALCOHOL DEPENDENCE IS RELATED TO OVERALL INTERNALIZING PSYCHOPATHOLOGY. Alcoholism: Clinical and Experimental Research, $\quad 36(2), \quad 325-331$. https://doi.org/10.1111/j.1530-

0277.2011.01604.x

Leigh, B. (1989a). In search of the seven dwarves: Issues of measurement and meaning in alcohol expectancy research. Psychological Bulletin, 105, 361-373. https://doi.org/10.1037/00332909.105.3.361

Leigh, B. (1989b). In search of the seven dwarves: Issues of measurement and meaning in alcohol expectancy research. Psychological Bulletin, 105, 361-373. https://doi.org/10.1037/00332909.105.3.361
Lewis, M., Litt, D., King, K., Fairlie, A., Waldron, K., Garcia, T., \& Lee, C. (2020). Examining the ecological validity of the prototype willingness model for adolescent and young adult alcohol use. Psychology of Addictive Behaviors, 34, 293-302. https://doi.org/10.1037/adb0000533

Litt, M., Kadden, R., Tennen, H., \& Petry, N. (2020). Individualized assessment and treatment program (IATP) for cannabis use disorder: Randomized controlled trial with and without contingency management. Psychology of Addictive Behaviors, $\quad 34, \quad 40-51$ https://doi.org/10.1037/adb0000491

Littlefield, A., Jackson, K., \& Talley, A. (2012). Coping Motives, Negative Moods, and Time-toDrink: Exploring Alternative Analytic Models of Coping Motives as a Moderator of Daily Mood-Drinking Covariation. Addictive Behaviors, $\quad 37, \quad$ 1371-1376. https://doi.org/10.1016/j.addbeh.2012.05.020 Macht, M., \& Simons, G. (2011). Emotional eating. In Emotion regulation and well-being (pp. 281295). Springer. 
Mazar, A., \& Wood, W. (2022). Illusory Feelings, Elusive Habits: People Overlook Habits in Explanations of Behavior. Psychological Science, 33(4), 563-578. https://doi.org/10.1177/09567976211045345

McClelland, D., Koestner, R., \& Weinberger, J. (1989). How do self-attributed and implicit motives differ? Psychological Review, 96, 690-702. https://doi.org/10.1037/0033-295X.96.4.690

McGinley, J., \& Curran, P. (2014). Validity concerns with multiplying ordinal items defined by binned counts. Methodology, 10, 108-116. https://doi.org/10.1027/1614-2241/a000081

Mohr, C., Brannan, D., Wendt, S., Jacobs, L., Wright, R., \& Wang, M. (2013). Daily mood-drinking slopes as predictors: A new take on drinking motives and related outcomes. Psychology of Addictive Behaviors, 27, 944-955. https://doi.org/10.1037/a0032633

Mohr, D. C., Zhang, M., \& Schueller, S. M. (2017). Personal Sensing: Understanding Mental Health Using Ubiquitous Sensors and Machine Learning. Annual Review of Clinical Psychology, 13(1), 23-47. https://doi.org/10.1146/annurev-clinpsy-032816-044949
Molenaar, P. C. M. (2004). A Manifesto on Psychology as Idiographic Science: Bringing the Person Back Into Scientific Psychology, This Time Forever. Measurement: Interdisciplinary Research \& Perspective, 2(4), 201-218. https://doi.org/10.1207/s15366359mea0204_1

Morris, E. P., Stewart, S. H., \& Ham, L. S. (2005). The relationship between social anxiety disorder and alcohol use disorders: A critical review. Clinical Psychology Review, 25(6), 734-760. https://doi.org/10.1016/j.cpr.2005.05.004

Murphy, J., \& Mackillop, J. (2006). Relative Reinforcing Efficacy of Alcohol Among College Student Drinkers. Experimental and Clinical Psychopharmacology, $\quad 14, \quad 219-227$. https://doi.org/10.1037/1064-1297.14.2.219

Nisbett, R., \& Wilson, T. (1977). Telling more than we can know: Verbal reports on mental processes. Psychological Review, 84, 231-259. https://doi.org/10.1037/0033-295X.84.3.231 
O’Donnell, R., Richardson, B., Fuller-Tyskiewicz, M., Liknaitzky, P., Arulkadacham, L., Dvorak, R., \& Staiger, P. (2019). Ecological momentary assessment of drinking in young adults: An investigation into social context, affect and motives. Addictive Behaviors, 98, 106019. https://doi.org/10.1016/j.addbeh.2019.06.008

O’Hara, R., Armeli, S., \& Tennen, H. (2014). Drinkingto-Cope Motivation and Negative MoodDrinking Contingencies in a Daily Diary Study of College Students. Journal of Studies on Alcohol and Drugs, 75, 606-614. https://doi.org/10.15288/jsad.2014.75.606

Open Science Collaboration. (2015). Estimating the reproducibility of psychological science. Science, $\quad 349, \quad$ aac4716. https://doi.org/10.1126/science.aac4716

Park, C., Armeli, S., \& Tennen, H. (2004). The Daily Stress and Coping Process and Alcohol Use among College Students. Journal of Studies on Alcohol, $\quad$ 65, 126-135. https://doi.org/10.15288/jsa.2004.65.126
Piccirillo, M. L., \& Rodebaugh, T. L. (2019). Foundations of idiographic methods in psychology and applications for psychotherapy. Clinical Psychology Review, 71, 90-100. https://doi.org/10.1016/j.cpr.2019.01.002

R Core Team. (2021). R: A language and environment for statistical computing (4.0.5). R Foundation for Statistical Computing.

Rehm, J., Mathers, C., Popova, S., Thavorncharoensap, M., Teerawattananon, Y., \& Patra, J. (2009). Global burden of disease and injury and economic cost attributable to alcohol use and alcohol-use disorders. The Lancet, 373, 22232233. https://doi.org/10.1016/S01406736(09)60746-7

Ren, B., Balkind, E. G., Pastro, B., Israel, E. S., Pizzagalli, D. A., Rahimi-Eichi, H., Baker, J. T., \& Webb, C. A. (2022). Predicting states of elevated negative affect in adolescents from smartphone sensors: A novel personalized machine learning approach. Psychological Medicine, https://doi.org/10.1017/S0033291722002161

Revelle, W. (2016). psych: Procedures for Personality and Psychological Research (1.6.4). Northwestern University. 
Room, R., Mäkelä, P., Benegal, V., Greenfield, T. K., Hettige, S., Tumwesigye, N. M., \& Wilsnack, R. (2012). Times to drink: Cross-cultural variations in drinking in the rhythm of the week. International Journal of Public Health, 57(1), 107-117. https://doi.org/10.1007/s00038-0110259-3

Russell, J. (1980). A circumplex model of affect. Journal of Personality and Social Psychology, 39, 1161-1178. https://doi.org/10.1037/h0077714

Russell, M., Linden-Carmichael, A., Lanza, S., Fair, E., Sher, K., \& Piasecki, T. (2020). Affect Relative to Day-Level Drinking Initiation: Analyzing Ecological Momentary Assessment Data With Multilevel Spline Modeling. Psychology of Addictive Behaviors, 34, 434-446. https://doi.org/10.1037/adb0000550

Sacco, P., Burruss, S., Smith, C., Kuerbis, A., Harrington, D., Moore, A., \& Resnick, B. (2015). Drinking behavior among older adults at a continuing care retirement community: Affective and motivational influences. Aging \& Mental Health, $\quad$ 19, 279-289. https://doi.org/10.1080/13607863.2014.93330 7

7
SAMHSA. (2021). Key substance use and mental health indicators in the United States: Results from the 2020 National Survey on Drug Use and Health. Substance Abuse and Mental Health Services Administration.

Sayette, M. (2017). The effects of alcohol on emotion in social drinkers. Behaviour Research and Therapy, $\quad 88, \quad 76-89$. https://doi.org/10.1016/j.brat.2016.06.005.

Serre, F., Fatseas, M., Swendsen, J., \& Auriacombe, M. (2015). Ecological momentary assessment in the investigation of craving and substance use in daily life: A systematic review. Drug and Alcohol Dependence, 148, 1-20. https://doi.org/10.1016/j.drugalcdep.2014.12.024

Shadur, J. M., Hussong, A. M., \& Haroon, M. (2015). Negative affect variability and adolescent selfmedication: The role of the peer context: Peer context and self-medication. Drug and Alcohol Review, $\quad 34(6), \quad$ 571-580. https://doi.org/10.1111/dar.12260 
Sharpe, B., Simms, L., \& Wright, A. (2020). Impulsivity, affect, and stress in daily life: Examining a cascade model of urgency. Journal of Personality Disorders, $\quad 34, \quad 465$. https://doi.org/10.1521/pedi_2020_34_465

Sher, K. J. (1991). Children of alcoholics: A critical appraisal of theory and research. University of Chicago Press.

Shiffman, S. (2009). Ecological Momentary Assessment (EMA) in Studies of Substance Use. Psychological Assessment, 21, 486-497. https://doi.org/10.1037/a0017074

Shrout, P., \& Lane, S. (2012). Psychometrics. In Handbook of research methods for studying daily life. The Guilford Press.

Simons, D., Shoda, Y., \& Lindsay, S. (2017). Constraints on Generality (COG): A Proposed Addition to All Empirical Papers. Perspectives on Psychological Science, 12, 1123-1128. https://doi.org/10.1177/1745691617708630
Simons, J., Dvorak, R., Batien, B., \& Wray, T. (2010). Event-level associations between affect, alcohol intoxication, and acute dependence symptoms: Effects of urgency, self-control, and drinking experience. Addictive Behaviors, 35, 1045-1053.

https://doi.org/10.1016/j.addbeh.2010.07.001

Simons, J., Gaher, R., Oliver, M., Bush, J., \& Palmer, M. (2005). An experience sampling study of associations between affect and alcohol use and problems among college students. Journal of Studies on Alcohol and Drugs, 66, 459-469. https://doi.org/10.15288/jsa.2005.66.459

Skinner, B. F. (1969). Contingencies of reinforcement. Appleton-Century-Crofts.

Smith, A. (2013). Effects of caffeine and alcohol on mood and performance changes following consumption of lager. Psychopharmacology, 227, 595-604. https://doi.org/10.1007/s00213-013$2991-2$ 
Smyth, J. M., Wonderlich, S. A., Heron, K. E., Sliwinski, M. J., Crosby, R. D., Mitchell, J. E., \& Engel, S. G. (2007). Daily and momentary mood and stress are associated with binge eating and vomiting in bulimia nervosa patients in the natural environment. Journal of Consulting and Clinical Psychology, 75(4), 629-638.

Stasiewicz, P., Bradizza, C., Schlauch, R., Coffey, S., Gulliver, S., Gudleski, G., \& Bole, C. (2013). Affect regulation training (ART) for alcohol use disorders: Development of a novel intervention for negative affect drinkers. Journal of Substance Abuse Treatment, 45, 433-443. https://doi.org/10.1016/j.jsat.2013.05.012

Stevens, A., Blanchard, B., Talley, A., Brown, J., Halvorson, M., Janssen, T., King, K., \& Littlefield, A. (2020). State-level impulsivity, affect, and alcohol: A psychometric evaluation of the momentary impulsivity scale across two intensive longitudinal samples. Journal of Research in Personality, 85. https://doi.org/10.1016/j.jrp.2020.103914
Stevenson, B., Dvorak, R., Kramer, M., Peterson, R., Dunn, M., Leary, A., \& Pinto, D. (2019). Within- and Between-Person Associations From Mood to Alcohol Consequences: The Mediating Role of Enhancement and Coping Drinking Motives. Journal of Abnormal Psychology, $\quad$ 128, $\quad$ 813-822. https://doi.org/10.1037/abn0000472

Sun, J., Rhemtulla, M., \& Vazire, S. (2021). Eavesdropping on Missing Data: What Are University Students Doing When They Miss Experience Sampling Reports? Personality and Social Psychology Bulletin, 47(11), 1535-1549. https://doi.org/10.1177/0146167220964639

Sutton, R., \& Barto, A. (2018). Reinforcement learning: An introduction. MIT Press.

Swendsen, J., Tennen, H., Carney, M., Affleck, G., Willard, A., \& Hromi, A. (2000). Mood and Alcohol Consumption: An Experience Sampling Test of the Self-Medication Hypothesis. Journal of Abnormal Psychology, 109, 198204. https://doi.org/10.1037/0021843X.109.2.198 
Tackett, J., Brandes, C., King, K., \& Markon, K. (2019). Psychology’s Replication Crisis and Clinical Psychological Science. Annual Review of Clinical Psychology, 15, 579-604. https://doi.org/10.1146/annurev-clinpsy050718-095710

Todd, M., Armeli, S., \& Tennen, H. (2009). Interpersonal Problems and Negative Mood as Predictors of Within-Day Time to Drinking. Psychology of Addictive Behaviors, 23, 205-215. https://doi.org/10.1037/a0014792

Todd, M., Tennen, H., Carney, M., Armeli, S., \& Affleck, G. (2004). Do We Know How We Cope? Relating Daily Coping Reports to Global and Time-Limited Retrospective Assessments. Journal of Personality and Social Psychology, 86, 310-319. https://doi.org/10.1037/00223514.86.2.310

Tovmasyan, A., Monk, R., \& Heim, D. (2022). Towards an affect intensity regulation hypothesis: Systematic review and metaanalyses of the relationship between affective states and alcohol consumption. Plos One, 17, e0262670. https://doi.org/10.1371/journal.pone.0262670
Trampe, D., Quoidbach, J., \& Taquet, M. (2015). Emotions in everyday life. Plos One, 10, e0145450. https://doi.org/10.1371/journal.pone.0145450

Treloar, H., Piasecki, T., McCarthy, D., Sher, K., \& Heath, A. (2015). Ecological evidence that affect and perceptions of drink effects depend on alcohol expectancies. Addiction, 110, 14321442. https://doi.org/10.1111/add.12982

van Hoorn, J., Fuligni, A., Crone, E., \& Galvan, A. (2016). Peer influence effects on risk-taking and prosocial decision-making in adolescence: Insights from neuroimaging studies. Current Opinion in Behavioral Sciences, 10, 59-64. https://doi.org/10.1016/j.cobeha.2016.05.007 van Rooij, I., \& Baggio, G. (2021). Theory Before the Test: How to Build High-Verisimilitude Explanatory Theories in Psychological Science. Perspectives on Psychological Science, 16, 682-697. https://doi.org/10.1177/1745691620970604 van Rooij, I., \& Blokpoel, M. (2020). Formalizing Verbal Theories. Social Psychology, 51, 285-298. https://doi.org/10.1027/1864-9335/a000428 
Vasishth, S., Nicenboim, B., Beckman, M., Li, F., \& Kong, E. J. (2018). Bayesian data analysis in the phonetic sciences: A tutorial introduction. Journal of Phonetics, 71, 147-161. https://doi.org/10.1016/j.wocn.2018.07.008

Vinci, C., Peltier, M., Shah, S., Kinsaul, J., Waldo, K., McVay, M., \& Copeland, A. (2014). Effects of a brief mindfulness intervention on negative affect and urge to drink among college student drinkers. Behaviour Research and Therapy, 59, 82-93. https://doi.org/10.1016/j.brat.2014.05.012

Votaw, V., \& Witkiewitz, K. (2021). Motives for Substance Use in Daily Life: A Systematic Review of Studies Using Ecological Momentary Assessment. Clinical Psychological Science, 9. https://doi.org/10.1177/2167702620978614

Waddell, J., Sher, K., \& Piasecki, T. (2021). Coping Motives and Negative Affect: An Ecological Study of the Antecedents of Alcohol Craving and Alcohol Use. Psychology of Addictive Behaviors. https://doi.org/10.1037/adb0000696
Wagenmakers, E.-J., Wetzels, R., Borsboom, D., van der Maas, H., \& Kievit, R. (2012). An agenda for purely confirmatory research. Perspectives on Psychological Science, 7, 627-633. https://doi.org/10.1177/1745691612463078

Watson, D. (2000). Mood and temperament. Guilford Press.

Watson, D., \& Clark, L. A. (1994). The PANAS-X: Manual for the Positive and Negative Affect Schedule-Expanded Form. University of Iowa.

Watson, D., Clark, L. A., \& Tellegen, A. (1988). Development and Validation of Brief Measures of Positive and Negative Affect: The PANAS Scales. Journal of Personality and Social Psychology, $\quad 54, \quad$ 1063-1070. https://doi.org/10.1037/0022-3514.54.6.1063

Wilkie, H., \& Stewart, S. (2005). Reinforcing Mood Effects of Alcohol in Coping and Enhancement Motivated Drinkers. Alcoholism: Clinical and Experimental Research, 29, 829-836. https://doi.org/10.1097/01.ALC.0000163498. 21044.CB 
Wills, T., \& Filer, M. (1996). Stress—Coping Model of Adolescent Substance Use. In Advances in Clinical Child Psychology (pp. 91-131). Plenum Press.

Witkiewitz, K., \& Villaroel, N. (2009). Dynamic association between negative affect and alcohol lapses following alcohol treatment. Journal of Consulting and Clinical Psychology, 77, 633644. https://doi.org/10.1037/a0015647

World Health Organization. (2018). Fact Sheet Alcohol. https://www.who.int/news-room/factsheets/detail/alcohol

Wright, A., \& Woods, W. (2020). Personalized Models of Psychopathology. Annual Review of Clinical Psychology, $\quad 16, \quad 49-74$. https://doi.org/10.1146/annurev-clinpsy$102419-125032$

Wycoff, A., Carpenter, R., Hepp, J., Lane, S., \& Trull, T. (2020). Drinking Motives Moderate DailyLife Associations Between Affect and Alcohol Use in Individuals With Borderline Personality Disorder. Psychology of Addictive Behaviors, 34, $745-755$. https://doi.org/10.1037/adb0000588
Yarkoni, T. (2020). The generalizability crisis. Behavioral and Brain Sciences, 1-37. https://doi.org/10.1017/S0140525X20001685

Zelenski, J., \& Larsen, R. (2000). The distribution of basic emotions in everyday life: A state and trait perspective from experience sampling data. Journal of Research in Personality, 34, 178-197. https://doi.org/10.1006/jrpe.1999.2275

Zevon, M., \& Tellegen, A. (1982). The structure of mood change: An idiographic/nomothetic analysis. Journal of Personality and Social Psychology, $\quad 43, \quad$ 111-122. https://doi.org/10.1037/0022-3514.43.1.111 


\section{Funding:}

Canadian Institutes of Health Research grant MOP-115104 (R O'Connor)

Canadian Institutes of Health Research grant MSH-122803 (R O'Connor)

John A. Hartford Foundation grant (P Sacco)

Loyola University Chicago Research Support grant (T DeHart)

National Institute for Occupational Safety and Health grant T03OH008435 (C Mohr)

National Institutes of Health grant F31AA023447 (R Carpenter)

National Institutes of Health grant R01AA025936 (K Creswell)

National Institutes of Health grant R01AA025969 (C Fairbairn)

National Institutes of Health grant R21AA024156 (A Fairlie)

National Institutes of Health grant F31AA024372 (F Goodman)

National Institutes of Health grant R01DA047247 (K King)

National Institutes of Health grant K01AA026854 (A Linden-Carmichael)

National Institutes of Health grant K01AA022938 (J Merrill)

National Institutes of Health grant K23AA024808 (H Treloar Padovano)

National Institutes of Health grant P60AA11998 (T Trull)

National Institutes of Health grant MH69472 (T Trull)

National Institutes of Health grant K01DA035153 (N Gottfredson)

National Institutes of Health grant P50DA039838 (A Linden-Carmichael)

National Institutes of Health grant K01DA047417 (D Lydon-Staley)

National Institutes of Health grant T32DA037183 (M Kushner)

National Institutes of Health grant R21DA038163 (A Moore)
National Institutes of Health grant K12DA000167 (M Potenza, S O’Malley)

National Institutes of Health grant R01AA025451 (B Bartholow, T Piasecki)

National Institutes of Health grant P50AA03510 (V Hesselbrock)

National Institutes of Health grant K01AA13938 (K Jackson)

National Institutes of Health grant K02AA028832 (K King)

National Institutes of Health grant T32AA007455 (M Larimer)

National Institutes of Health grant R01AA025037 (C Lee, M Patrick)

National Institutes of Health grant R01AA025611 (M Lewis)

National Institutes of Health grant R01AA007850 (R Miranda)

National Institutes of Health grant R21AA017273 (R Miranda)

National Institutes of Health grant R03AA014598 (C Mohr)

National Institutes of Health grant R29AA09917 (C Mohr)

National Institutes of Health grant T32AA07290 (C Mohr)

National Institutes of Health grant P01AA019072 (P Monti)

National Institutes of Health grant R01AA015553 (J Morgenstern)

National Institutes of Health grant R01AA020077 (J Morgenstern)

National Institutes of Health grant R21AA017135 (J Morgenstern)

National Institutes of Health grant R01AA016621 (S O’Malley)

National Institutes of Health grant K99AA029459 (M Piccirillo)

National Institutes of Health grant F31AA022227 (N Scaglione)

National Institutes of Health grant R21AA018336 (K Witkiewitz) 
Portuguese State Budget Foundation for Science and Technology grant UIDB/PSI/01662/2020 (T Freire)

University of Washington Population Health Covid-19 Rapid Response grant (J Kanter, A Kuczynski)

U.S. Department of Defense grant W81XWH13-2-0020 (C Mohr)

SANPSY laboratory core support grant CNRS USR 3413 (M Auriacombe)

Social Sciences and Humanities Research Council of Canada grant (N Galambos)

Social Sciences and Humanities Research Council of Canada grant (A Howard)

\section{Author contributions:}

Conceptualization: Jonas Dora, Marilyn Piccirillo, Kate Foster, Kevin King

Data curation: All authors

Formal analysis: Jonas Dora

Funding acquisition: Kevin King

Investigation: All authors
Methodology: All authors

Project administration: Jonas Dora, Kevin King

Resources: All authors

Software: Jonas Dora

Supervision: Kevin King

Validation: Kevin King

Visualization: Jonas Dora

Writing - original draft: Jonas Dora, Marilyn Piccirillo, Kate Foster, Kevin King

Writing - review \& editing: All authors

Competing interests: Authors declare that they have no competing interests.

Data and materials availability: We do not have permission to share the raw data from all 69 studies included in this meta-analysis. Our analysis code and the output of our meta-analytic models are available at https://osf.io/jcr2q/. 